\title{
A Pliocene-Pleistocene stack of 57 globally distributed benthic $\delta^{18} \mathrm{O}$ records
}

\author{
Lorraine E. Lisiecki \\ Department of Geological Sciences, Brown University, Providence, Rhode Island, USA \\ Maureen E. Raymo \\ Department of Earth Sciences, Boston University, Boston, Massachusetts, USA
}

Received 8 July 2004; revised 9 November 2004; accepted 23 November 2004; published 18 January 2005.

[1] We present a 5.3-Myr stack (the "LR04" stack) of benthic $\delta^{18} \mathrm{O}$ records from 57 globally distributed sites aligned by an automated graphic correlation algorithm. This is the first benthic $\delta^{18} \mathrm{O}$ stack composed of more than three records to extend beyond $850 \mathrm{ka}$, and we use its improved signal quality to identify 24 new marine isotope stages in the early Pliocene. We also present a new LR04 age model for the Pliocene-Pleistocene derived from tuning the $\delta^{18} \mathrm{O}$ stack to a simple ice model based on 21 June insolation at $65^{\circ} \mathrm{N}$. Stacked sedimentation rates provide additional age model constraints to prevent overtuning. Despite a conservative tuning strategy, the LR04 benthic stack exhibits significant coherency with insolation in the obliquity band throughout the entire 5.3 Myr and in the precession band for more than half of the record. The LR04 stack contains significantly more variance in benthic $\delta^{18} \mathrm{O}$ than previously published stacks of the late Pleistocene as the result of higherresolution records, a better alignment technique, and a greater percentage of records from the Atlantic. Finally, the relative phases of the stack's 41- and 23-kyr components suggest that the precession component of $\delta^{18} \mathrm{O}$ from $2.7-1.6 \mathrm{Ma}$ is primarily a deep-water temperature signal and that the phase of $\delta^{18} \mathrm{O}$ precession response changed suddenly at $1.6 \mathrm{Ma}$.

Citation: Lisiecki, L. E., and M. E. Raymo (2005), A Pliocene-Pleistocene stack of 57 globally distributed benthic $\delta^{18} \mathrm{O}$ records, Paleoceanography, 20, PA1003, doi:10.1029/2004PA001071.

\section{Introduction}

[2] Alley [2003] recently called for a paleoceanographic "type section" to which all paleoceanographic measurements could be compared, in the same way that researchers have used data gathered by the Second Greenland Ice Sheet Project (GISP2) and Greenland Ice Core Project (GRIP) in studies of the last glacial cycle. A type section which provides a common timescale and reference of comparison for all paleoceanographic records would improve communication within the community and elucidate subtle differences among the evergrowing number of paleoceanographic records. Here we present a new 5.3-Myr benthic $\delta^{18} \mathrm{O}$ stack (the "LR04" stack), which we propose would make an excellent paleoceanographic type section for the Pliocene-Pleistocene.

[3] Alley [2003] describes the ideal type section as high in resolution, multiply replicated by different laboratories, containing multiple paleoclimate proxies, and spanning as much time as possible. The LR04 stack contains over 38,000 individual $\delta^{18} \mathrm{O}$ measurements from 57 sites, sampled at many different laboratories. Because this stack incorporates information from so many sites, it has a higher signal-to-noise ratio than any previous $\delta^{18} \mathrm{O}$ record and more accurately reflects changes in global climate.

Copyright 2005 by the American Geophysical Union. 0883-8305/05/2004PA001071
The stack's resolution of orbital-scale (23-kyr) features in the Pleistocene is comparable to that of millennial-scale $(1.5-\mathrm{kyr})$ features in the GISP2 $\delta^{18} \mathrm{O}$ record [Grootes et al., 1993], with 10-20 samples per cycle. The stack spans the entire Pliocene-Pleistocene with error bars averaging only $0.1 \%$. We also use the LR04 stack to develop a conservatively tuned $\delta^{18} \mathrm{O}$ timescale, which minimizes deviations in globally averaged sedimentation rates. Although the LR04 stack contains only one paleoceanographic parameter, any paleoclimate proxy taken from a marine core with reliable $\delta^{18} \mathrm{O}$ data can easily be aligned to the LR04 stack through the use of automated graphic correlation software [e.g., Lisiecki and Lisiecki, 2002]. The LR04 stack and supplemental results are archived at the National Geophysical Data Center (http:/www.ngdc.noaa.gov/paleo/ paleocean.html).

[4] In the following section we provide background information on $\delta^{18} \mathrm{O}$ and previously published stacks. Section 3 describes the $\delta^{18} \mathrm{O}$ data used in the LR04 stack. Section 4 contains a detailed description of the stack's construction and demonstrates the effectiveness of our graphic correlation and stacking techniques in reducing the noise level of $\delta{ }^{18} \mathrm{O}$-like signals. Section 5 describes the creation of the orbitally tuned LR04 age model, which is additionally constrained by two measures of global sedimentation rate. In section 6 we present specific $\delta^{18} \mathrm{O}$ estimates with error bars and define 24 new marine isotope stages (MIS) in the early Pliocene. We also compare the LR04 stack to four previously 
Table 1. Notable $\delta^{18} \mathrm{O}$ Stacks

\begin{tabular}{lcc}
\hline \multicolumn{1}{c}{ Stack } & $\begin{array}{c}\text { Component } \\
\delta^{18} \mathrm{O} \mathrm{Records}^{\mathrm{a}}\end{array}$ & $\begin{array}{c}\text { Approximate } \\
\text { Length }\end{array}$ \\
\hline SPECMAP $^{\mathrm{b}}$ & $5 \mathrm{p}$. & $750 \mathrm{kyr}$ \\
Pisias et al. $[1984]$ & $5 \mathrm{~b}$. & $300 \mathrm{kyr}^{\mathrm{c}}$ \\
Prell et al. $[1986]$ & $11 \mathrm{p} ., 2 \mathrm{~b}$. & $750 \mathrm{kyr}^{\mathrm{c}}$ \\
Williams et al. $[1988]$ & $3 \mathrm{p} ., 1 \mathrm{~b}$. & $1.9 \mathrm{Myr}$ \\
Raymo et al. $[1990]$ & $3 \mathrm{~b}$. & $2.5 \mathrm{Myr}$ \\
Bassinot et al. $[1994]$ & $2 \mathrm{p}$. & $600 \mathrm{kyr}$ \\
S95 Composite & $3 \mathrm{~b} .($ in series) & $860 \mathrm{kyr}$ \\
Karner et al. [2002] & $6-13 \mathrm{~b}$. & $780 \mathrm{kyr}$ \\
HW04 & $5 \mathrm{p} ., 5 \mathrm{~b}$. (EOF) & $5.3 \mathrm{Myr}$ \\
LR04 (this study) $^{\mathrm{d}}$ & $57 \mathrm{~b}$. &
\end{tabular}

${ }^{\mathrm{a} P l a n k t o n i c}$ (p.) or benthic (b.).

${ }^{\mathrm{b}}$ From Imbrie et al. [1984].

${ }^{\mathrm{c}}$ No timescale assigned to stack.

${ }^{\mathrm{d}}$ From Shackleton [1995].

${ }^{\mathrm{e}}$ From Huybers and Wunsch [2004].

published $\delta^{18} \mathrm{O}$ stacks. Finally, in section 7 we discuss the uncertainty in the LR04 age model and interpret changes in the phase of benthic $\delta^{18} \mathrm{O}$ relative to precession.

\section{Stacks of $\delta^{18} \mathrm{O}$}

[5] Time series of the $\delta^{18} \mathrm{O}$ of foraminiferal calcite tests provide an important record of climate change. Foraminiferal $\delta^{18} \mathrm{O}$ is a function of the temperature and $\delta^{18} \mathrm{O}$ of the water in which it forms, and the $\delta^{18} \mathrm{O}$ of seawater is a function of global ice volume and water salinity. (The scaling between $\delta^{18} \mathrm{O}$ and these two factors can vary with patterns of sea ice formation, evaporation, and precipitation.) Owing to the observed similarity of most marine $\delta^{18} \mathrm{O}$ records and the global nature of the ice volume signal, $\delta^{18} \mathrm{O}$ measurements also serve as the primary means for placing marine climate records on a common timescale. Stacks, which are averages of $\delta^{18} \mathrm{O}$ records from multiple sites, improve the signal-to-noise ratio of the climate signal and make useful alignment targets and references for comparison. Benthic $\delta^{18} \mathrm{O}$ records should produce a better stack than planktonic records because the deep ocean is more uniform in temperature and salinity than surface water. Less local and regional climatic variability improves the accuracy of alignment and produces a better estimate of average $\delta^{18} \mathrm{O}$ change. While a stack alone cannot address the relative contributions of ice volume and temperature to the benthic $\delta^{18} \mathrm{O}$ signal, a good stack does provide an accurate estimate of how much total change must be explained.

[6] Table 1 contains a summary of some notable $\delta^{18} \mathrm{O}$ stacks. The most widely used stack is the one constructed by SPECMAP [Imbrie et al., 1984] (hereinafter referred to as SPECMAP), which is composed of five planktonic records and extends back to $\sim 750 \mathrm{kyr}$ ago (ka). While studies support the basic structure of this stack and its timescale back to $\sim 625$ ka [e.g., Shackleton et al., 1990; Pisias et al., 1990; Raymo, 1997; Huybers and Wunsch, 2004], many longer and higher resolution $\delta^{18} \mathrm{O}$ records are now available. Another important $\delta^{18} \mathrm{O}$ reference signal is the 6-Myr composite benthic $\delta^{18} \mathrm{O}$ sequence of Shackleton [1995] (hereinafter referred to as S95), which was constructed by placing high-resolution $\delta^{18} \mathrm{O}$ records from three different sites (V19-30, ODP 677, and ODP 846) in series. Karner et al. [2002] construct an 860-kyr "minimally tuned" benthic stack by aligning the 41-kyr components of 13 benthic records. However, they present a second, tropical stack containing only six of these records because they find their alignment technique to be inadequate for cores with highly variable sedimentation rates. Last, Huybers and Wunsch [2004] recently published a depth-derived age model for the last $780 \mathrm{kyr}$ (hereinafter referred to as HW04), accompanied by the leading empirical orthogonal function (EOF1) of five planktonic and five benthic $\delta^{18} \mathrm{O}$ records. Their age model assumes that the average sedimentation rate across 21 cores was constant between 17 isotopic events, after applying a correction for the effects of down-core compaction. Many other age models have been created by tuning data from individual sites [e.g., Tiedemann et al., 1994; Tiedemann and Franz, 1997]; the proliferation of such age models can greatly complicate the comparison of data from different sites.

[7] The LR04 stack contains 57 benthic records aligned using a graphic correlation technique [Lisiecki and Lisiecki, 2002] and is the first benthic $\delta^{18} \mathrm{O}$ stack containing more than three records to extend beyond $850 \mathrm{ka}$. In section 6 , we compare the LR04 stack with the S95 composite, the SPECMAP stack, the minimally tuned tropical stack of Karner et al. [2002], and the depth-derived age model of HW04. We discuss several isotope stages for which the $\mathrm{S} 95$ composite is not representative of global mean $\delta^{18} \mathrm{O}$ as well as two likely errors in the S95 age model.

\section{Data}

[8] The stack presented in this paper contains benthic $\delta^{18} \mathrm{O}$ records from 57 globally distributed sites. These sites are well distributed in latitude, longitude, and depth in the Atlantic and Pacific and include two sites in the Indian Ocean (Figure 1). Most of the $\delta^{18} \mathrm{O}$ measurements in these records are from Uvigerina peregrina or Cibicidoides wuellerstorfi, with appropriate species offset corrections [Shackleton and Hall, 1984]. The included records vary widely in resolution and time span. The only benthic $\delta^{18} \mathrm{O}$ records purposefully excluded from the LR04 stack are those with sample spacings greater than $12 \mathrm{kyr}$, a resolution too low for accurate alignment. Our stacking technique, described below, is robust to the inclusion of records of varying quality because sites with higher resolution are more heavily weighted in the averaging process. The aligned $\delta^{18} \mathrm{O}$ records used in the stack are shown in Figure 2. The stack contains 47 records back to $0.4 \mathrm{Ma}, \sim 25$ records from $1-$ $3 \mathrm{Ma}$, at least 12 records back to $4.9 \mathrm{Ma}$, and 5 records from 5-5.33 Ma. No one record represents more than $30 \%$ of the data in a 10-kyr interval except before $5 \mathrm{Ma}$, when Site 846 [Shackleton et al., 1995a] provides approximately $40 \%$ of the data. In total, the LR04 stack incorporates 38,229 individual $\delta^{18} \mathrm{O}$ measurements.

\section{Stack Construction}

\subsection{Graphic Correlation}

[9] Graphic correlation is the process of aligning paleoclimate signals based on the features within those signals [Prell et al., 1986], for example, by matching corresponding 


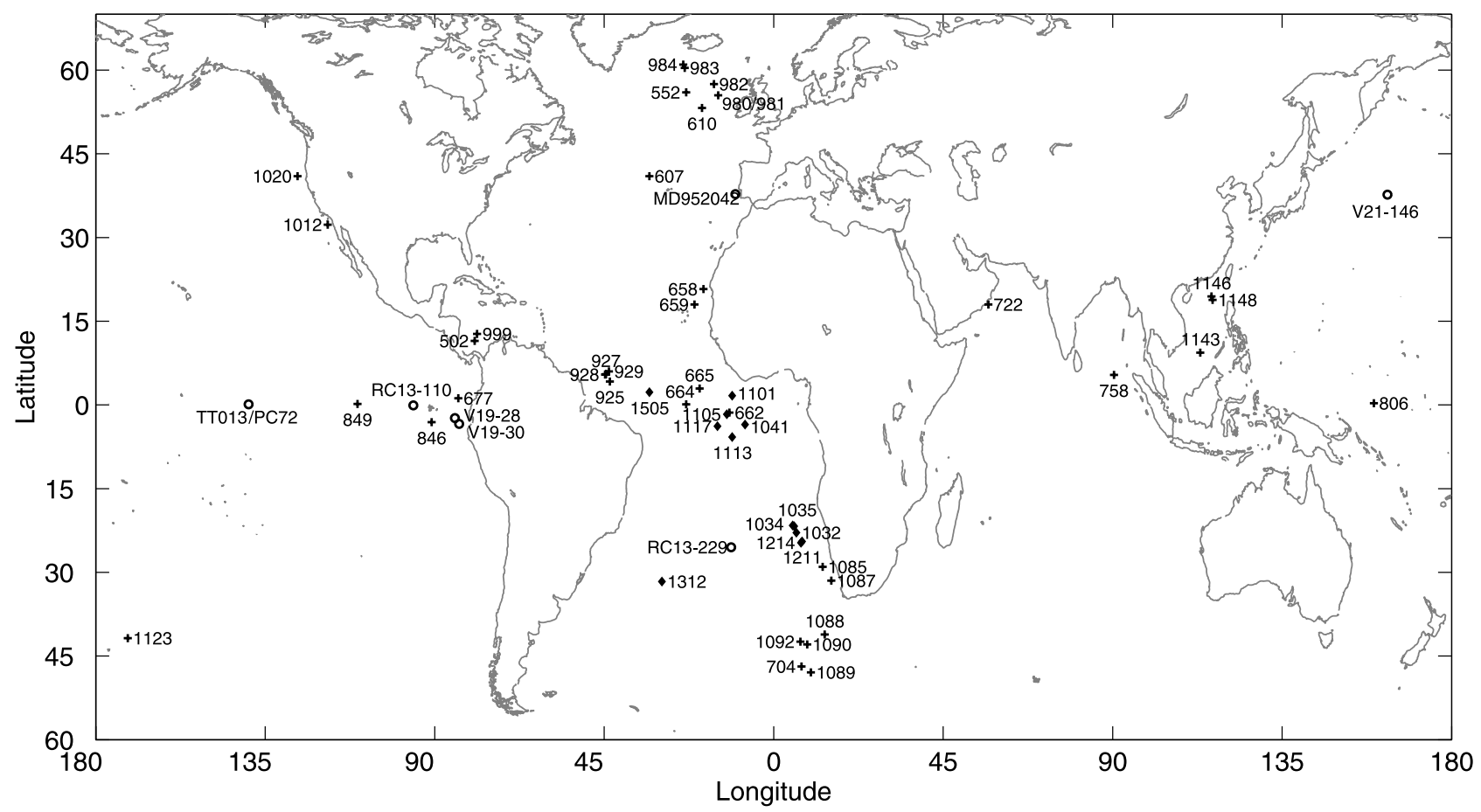

Figure 1. Location of the cores used in this study. Benthic $\delta^{18} \mathrm{O}$ data are taken from Deep-Sea Drilling Project (DSDP) and Ocean Drilling Program (ODP) sites (crosses), GeoB sites (diamonds), and others (circles).

peaks. Graphic correlation inherently requires some judgment to determine which features correspond to one another and to distinguish noise from isotopic features. Automated correlation algorithms provide the most objective correlation techniques because alignment criteria are explicit and applied consistently. However, each alignment must also be evaluated by eye because stratigraphic disturbances resulting from hiatuses, coring gaps, and duplicated sections can produce errors in the automated correlation.

[10] We align 57 benthic $\delta^{18} \mathrm{O}$ records using an automated graphic correlation program [Lisiecki and Lisiecki, 2002], which considers all possible alignments to find the best global fit and penalizes alignments based on extreme sedimentation rates and sudden sedimentation rate changes. Alignments are performed using normalized $\delta^{18} \mathrm{O}$ records to maximize the algorithm's accuracy. Each alignment is evaluated by eye and adjusted, if necessary, by changing the sedimentation rate penalties or adding tie points until a good alignment is achieved which agrees reasonably well with previously published age estimates (e.g., those derived from paleomagnetic reversals or biostratigraphic data). In general, we keep sedimentation rate penalties small because little is known about how linear sedimentation rates (LSR) vary with time. This allows the LSR at individual sites to vary a great deal and preserves as much coherent $\delta^{18} \mathrm{O}$ variation as possible. With our alignments and age model, the average standard deviation $(\sigma)$ in a site's LSR is $1.8 \mathrm{~cm} / \mathrm{kyr}$. As a percentage of each site's mean LSR, $\sigma$ averages $41 \%$ and ranges from $24 \%$ at Site GeoB 1041 to $164 \%$ at ODP Site 927 from 5.0-2.6 Ma.

[11] Graphic correlation allows the stack's construction to be largely independent of its assigned timescale and, con- sequently, any specific forcing model for $\delta^{18} \mathrm{O}$. However, stacking with graphic correlation does involve two assumptions: that each site records the same global $\delta^{18} \mathrm{O}$ signal with little phase difference and that the alignment procedure is not overly sensitive to noise. In support of the first assumption, each site does appear to record the same $\delta^{18} \mathrm{O}$ signal; the average correlation between the LR04 stack and individual records (after alignment) is 0.88 . Also, phase differences in $\delta^{18} \mathrm{O}$ between sites should be minimal because the average mixing time of the deep ocean is only $\sim 1$ kyr. Glacial ventilation rates are uncertain, but benthic-planktonic age differences at the last glacial maximum yield deep-water age estimates of $1.1 \mathrm{kyr}$ in the deep Atlantic [Keigwin and Schlegel, 2002] and $2 \mathrm{kyr}$ in the deep Pacific [Broecker et al., 2004]. Graphic correlation actually corrects for any potential mixing lags between sites to produce an estimate of the $\delta^{18} \mathrm{O}$ signal as if it had been recorded with the same phase everywhere.

[12] The assumption that alignments are insensitive to noise is a concern because sedimentation rates at individual sites are only loosely constrained in order to maximize the amplitude of isotopic features. Therefore we perform a series of simple experiments to test the ability of our alignment technique to reduce noise without artificially increasing signal amplitude. In the experiments, we construct test stacks from twenty noisy copies of a single isotope record. The noisy copies are created by the addition of white noise with standard deviations of $2 \mathrm{kyr}$ and $0.2 \%$ to the ages and $\delta^{18} \mathrm{O}$ values of the initial signal. We also add white noise $(\sigma=0.15 \%)$ to the $\delta^{18} \mathrm{O}$ values of each alignment target before applying our graphic correlation and stacking algorithms. Figure 3 shows test 


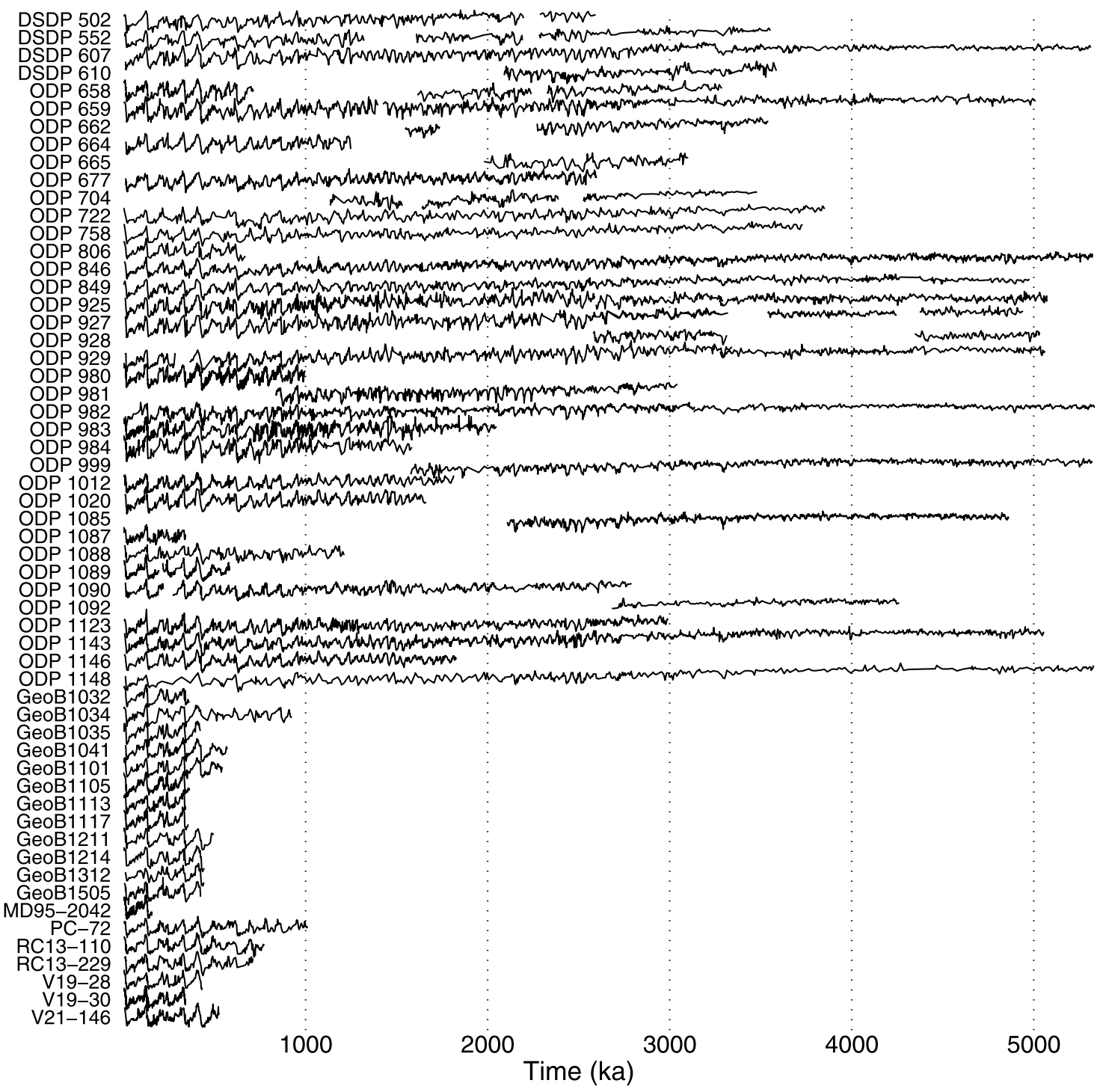

Figure 2. Graphically aligned benthic $\delta^{18} \mathrm{O}$ data, plotted with their original variance but offset vertically. Data are from Sites 502 [deMenocal et al., 1992], 552 [Shackleton and Hall, 1984], 607 [Ruddiman et al., 1989; Raymo et al., 1989; Raymo et al., 1992; this study], 610 [Raymo et al., 1992], 658 [Tiedemann, 1991], 659 [Tiedemann et al., 1994], 662 (this study), 664 [Raymo et al., 1997], 665 [Curry and Miller, 1989], 677 [Shackleton et al., 1990], 704 [Hodell and Venz, 1992], 722 [Clemens et al., 1996], 758 [Chen et al., 1995], 806 [Berger et al., 1993], 846 [Mix et al., 1995a; Shackleton et al., 1995a], 849 [Mix et al., 1995b], 925 [Bickert et al., 1997; Billups et al., 1998; Franz, 1999], 927 [Bickert et al., 1997; Franz, 1999], 928 [Franz, 1999], 929 [Bickert et al., 1997; Billups et al., 1998; Franz, 1999], 980 [Oppo et al., 1998; McManus et al., 1999; Flower et al., 2000], 981 [Mc Intyre et al., 1999; Raymo et al., 2004], 982 [Venz et al., 1999; Venz and Hodell, 2002; this study], 983 [Mc Intyre et al., 1999; Raymo et al., 2004], 984 [Raymo et al., 2004], 999 [Haug and Tiedemann, 1998], 1012 and 1020 [Herbert et al., 2001; Z. Liu, personal communication, 2002], 1085 (D. Andreasen, personal communication, 2002), 1087 [Pierre et al., 2001], 1088 [Hodell et al., 2003], 1089 [Hodell et al., 2001], 1090 [Venz and Hodell, 2002], 1092 [Andersson et al., 2002], 1123 [Hall et al., 2001; Harris, 2002], 1143 [Tian et al., 2002], 1146 (S. Clemens, personal communication, 2002), 1148 [Jian et al., 2003], GeoB 1032, 1041, 1101 [Bickert and Wefer, 1996], GeoB 1113 [Sarnthein et al., 1994], GeoB 1117, 1211, 1214 [Bickert and Wefer, 1996], GeoB 1312 [Hale and Pflaumann, 1999], GeoB 1505 [Zabel et al., 1999], MD95-2042 [Shackleton et al., 2000], PC72 [Murray et al., 2000], RC13-110 [Mix et al., 1991; Imbrie et al., 1992], RC13-229 [Oppo et al., 1990], V19-28 [Ninkovitch and Shackleton, 1975], V19-30 [Shackleton and Pisias, 1985], V21-146 [Hovan et al., 1991]. 

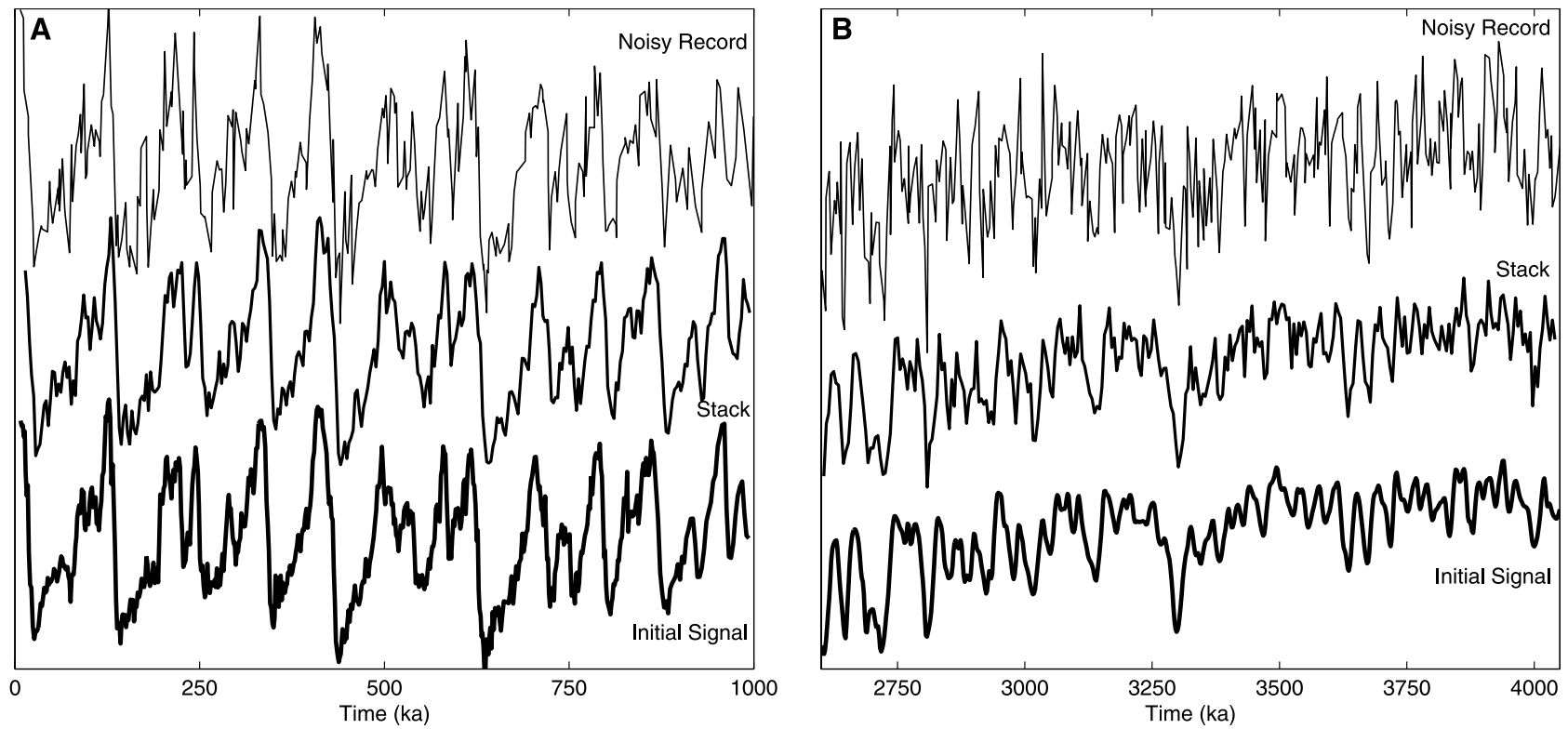

Figure 3. Test of alignment and stacking technique for (a) Pleistocene and (b) Pliocene $\delta^{18} \mathrm{O}$. (top) One of 20 artificial noisy $\delta^{18} \mathrm{O}$ records used to produce (middle) a test stack, which is compared to (bottom) the initial $\delta^{18} \mathrm{O}$ signal. (See text for discussion.)

stacks generated from initial signals of Pleistocene $(\sigma=$ $0.43 \%$ ) and Pliocene $\left(\sigma=0.21 \%\right.$ ) $\delta^{18} \mathrm{O}$ data. In 400 replications, the stacks' error relative to the initial isotope signal (for either time period) has a standard deviation of $0.09 \pm 0.01 \%$, less than the noise in the alignment target and half that of the noisy records used to construct the stack. Experiments performed with red noise produce similar results. Stacking records of varying resolution (while holding the total number of data points constant) tends to reduce stack error by improving the alignment accuracy of high resolution records. In conclusion, the extraordinary similarity between the test stacks and the initial isotope signals demonstrates the ability of our alignment and stacking technique to increase the signalto-noise ratio of Pleistocene and Pliocene $\delta^{18} \mathrm{O}$ records.

\subsection{Stacking}

[13] The alignment process for the stack's construction is iterative. Our initial alignment targets are high-resolution segments of seven $\delta^{18} \mathrm{O}$ records: GeoB1041 from 0$0.15 \mathrm{Ma}$, ODP Site 1012 from 0-0.6 Ma, ODP Site 927 from 0-1.4 Ma, ODP Site 677 from 0-2.0 Ma, ODP Site 849 from 1.7-3.6 Ma, ODP Site 846 from 2.7-5.3 Ma, and ODP Site 999 from 3.3-5.3 Ma. Each $\delta^{18} \mathrm{O}$ record is first aligned to these targets in the depth domain to create seven short stacks. In the intervals where these stacks overlap, we observe that the features of the stacks are largely independent of which site serves as the alignment target.

[14] The seven stacks are assigned timescales taken from the S95 composite and spliced together to form a transitional stack spanning the entire 5.3-Myr interval. In constructing the transitional stack, we select portions of the short stacks which are most representative of the component records and which best resolve substage features. These comparisons help prevent hiatuses, sediment disturbances, and splicing errors within an alignment target from affecting the final stack. Where possible, we also avoid using the first and last $5 \%$ of each stack due to added uncertainty in the graphic correlation [Lisiecki and Lisiecki, 2002]. After creating the transitional stack, we make a few adjustments to its age model to eliminate large deviations in the sites' sedimentation rates and perform a final set of alignments using the transitional stack as the alignment target.

[15] The LR04 stack (Figure 4) is the average of all $\delta^{18} \mathrm{O}$ records aligned to the transitional stack. This final step improves alignment accuracy because the transitional stack resembles the average $\delta^{18} \mathrm{O}$ curve more closely than any individual site does. Also, because the transitional stack spans the entire 5.3 Myr, most of our records could be aligned to it in one piece, reducing the potential for errors where the shorter stacks join together. The $\delta^{18} \mathrm{O}$ records from eleven sites are aligned to the stack in multiple pieces because they are greater than $3 \mathrm{Myr}$ in length or contain large gaps. In Figure 4 we show the final LR04 stack assigned to the LR04 age model, described in section 5 .

[16] Our stacking technique is similar to one used by Pisias et al. [1984]. The stack's time domain is divided into small, equally spaced intervals (Table 2), and an average is taken of all $\delta^{18} \mathrm{O}$ measurements lying within each time interval. Therefore each point in the stack is the average of all of the data which fall in a particular time interval. Unlike the averaging of evenly interpolated records, this technique weights high-resolution records more heavily and prevents interpolation across gaps or hiatuses from affecting the stack. The final LR04 stack is composed of four sections of different resolution due to the decreasing number of records available in the more distant past. Table 2 provides the interval size (equivalent to stack resolution) and data statistics for each section. For any given time interval, the 

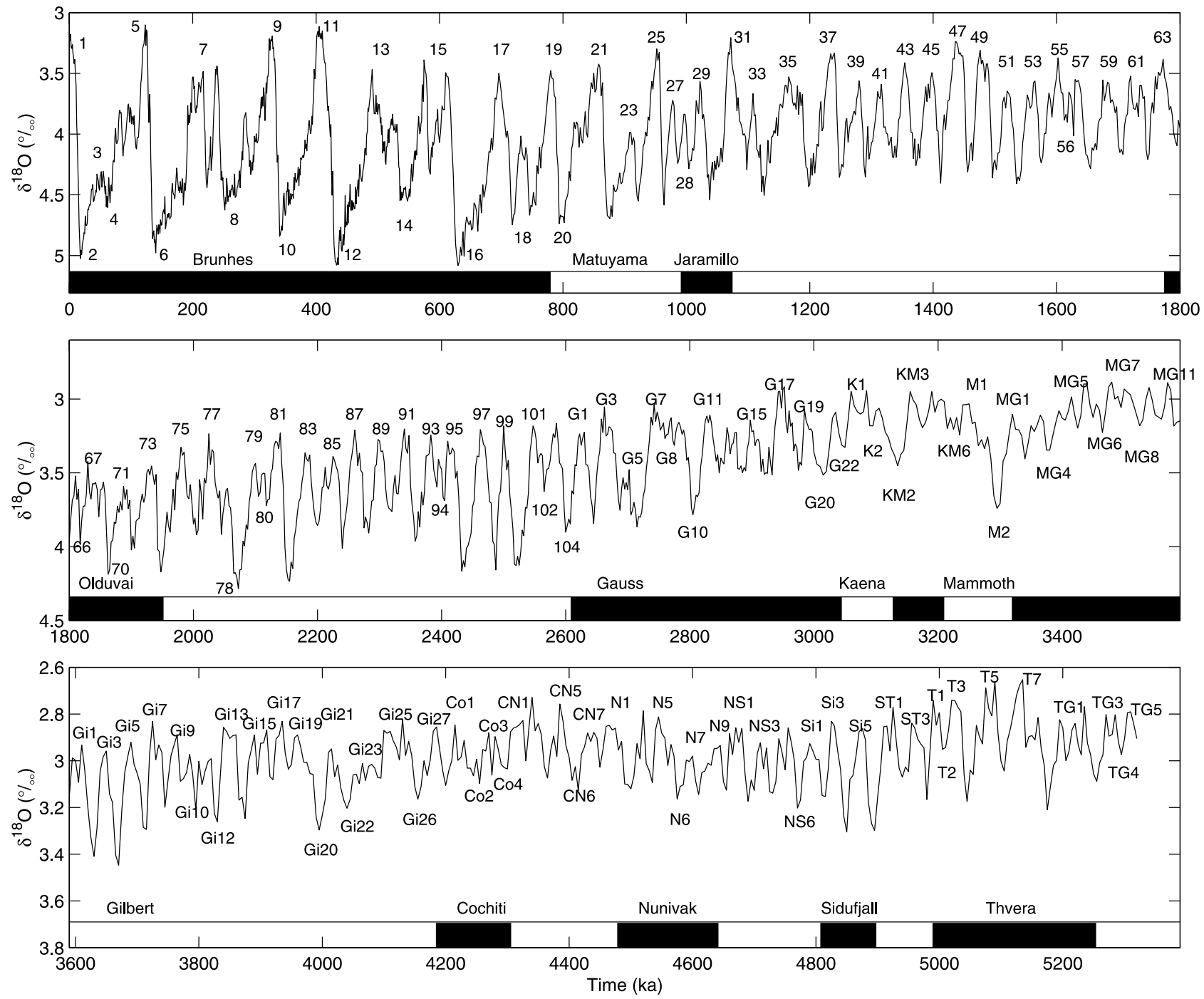

Figure 4. The LR04 benthic $\delta^{18} \mathrm{O}$ stack constructed by the graphic correlation of 57 globally distributed benthic $\delta^{18} \mathrm{O}$ records. The stack is plotted using the LR04 age model described in section 5 and with new MIS labels for the early Pliocene (section 6.2). Note that the scale of the vertical axis changes across panels.

concentration of data used in the LR04 stack is at least twice as high as in any previous stack or individual $\delta^{18} \mathrm{O}$ record spanning that interval. The stack's resolution is comparable to previous stacks but is less than half that of the highestresolution records.

[17] The LR04 stack is simply the average of the aligned benthic $\delta^{18} \mathrm{O}$ records. We do not adjust the mean or variance of the records, except to make species offset corrections. We choose not to adjust the isotope curves based on their modern bottom water temperatures because the temperature differences between sites may have changed dramatically over the last 5.3 Myr. We also do not weight the records based on their spatial distribution. The majority of records are from the Atlantic Ocean, and the number of sites in the stack varies with time, changing the relative weighting of different regions. However, we observe that regional differences in benthic $\delta^{18} \mathrm{O}$ are typically less than $0.3 \%$ (less than
$0.15 \%$ after $0.6 \mathrm{Ma}$ ), and we are currently developing a detailed description of regional $\delta^{18} \mathrm{O}$ variability.

\section{Age Model}

[18] Because the LR04 stack is constructed by graphic correlation, its stratigraphic features are essentially independent of any timescale. Below we describe the construction of an age model which takes advantage of the high signal-to-noise ratio of the stack and analysis of the sedimentation rates at 57 sites. However, almost any age model could be applied to the LR04 stack. This flexibility allows the stack to be adapted to alternate models of $\delta^{18} \mathrm{O}$ response or to improvements in age estimates.

[19] We construct the LR04 age model by aligning our benthic $\delta^{18} \mathrm{O}$ stack to a simple model of ice volume while considering the average (stacked) sedimentation rate of 
Table 2. Interval Characteristics

\begin{tabular}{lcccc}
\hline Time, Ma & $\begin{array}{c}\text { Interval } \\
\text { Size, kyr }\end{array}$ & $\begin{array}{c}\text { Mean Number of Data } \\
\text { Points per Interval }\end{array}$ & $\begin{array}{c}\text { Mean Standard Deviation } \\
\text { per Interval, \%o }\end{array}$ & $\begin{array}{c}\text { Mean Standard Error } \\
\text { per Interval, \%o }\end{array}$ \\
\hline $0-0.6$ & 1.0 & 30.6 & 0.22 & 0.05 \\
$0.6-1.5$ & 2.0 & 20.0 & 0.26 & 0.06 \\
$1.5-3.0$ & 2.5 & 16.5 & 0.26 & 0.06 \\
$3.0-5.3$ & 5.0 & 15.5 & 0.19 & 0.05 \\
\hline
\end{tabular}

the stack's 57 sediment cores. This age model is more reliable than one from a single $\delta{ }^{18} \mathrm{O}$ record because individual $\delta^{18} \mathrm{O}$ records have more noise and fewer constraints on linear sedimentation rates (LSR) than a stack. We seek to minimize changes in the stack's average LSR under the assumption that global sedimentation rates have been relatively stable. Constraining average LSR does not prevent individual sites from exhibiting highly variable sedimentation rates. Age-versusdepth plots and average sedimentation rates are often used to evaluate age models [e.g., Imbrie et al., 1984; Shackleton et al., 1990; Raymo, 1997] because timescale errors create LSR deviations at all sites while most sources of LSR variability are local or regional. Unlike Huybers and Wunsch [2004], we do not assume that average sedimentation rates are absolutely constant because the long-term climatic changes of the Pliocene-Pleistocene have likely had some effect on sedimentation rates. Therefore our tuning goals are to prevent rapid fluctuations in stacked LSR and to minimize its variance. By allowing sedimentation rates to vary slowly with time, we also eliminate the need to correct for sediment compaction except at the very top of the record.

\subsection{From 0 to $135 \mathrm{ka}$}

[20] While generally robust, our LSR tuning strategy is not effective for the most recent portion of the stack, where apparent sedimentation rates can be distorted by uncompacted sediments in the top few meters of a core [e.g., Skinner and McCave, 2003; Huybers and Wunsch, 2004]. Fortunately, reliable age estimates are available for this portion of the benthic $\delta^{18} \mathrm{O}$ record. The top $22 \mathrm{kyr}$ of the stack are dated by correlation to the ${ }^{14} \mathrm{C}$-dated benthic $\delta^{18} \mathrm{O}$ record, NA87-22 [Waelbroeck et al., 2001]. From $22-120 \mathrm{ka}$ the stack is aligned to the high-resolution benthic $\delta^{18} \mathrm{O}$ record of Site MD95-2042 [Shackleton et al., 2000], which is dated by correlating millennial-scale features in its planktonic $\delta^{18} \mathrm{O}$ to ice $\delta^{18} \mathrm{O}$ from the GRIP ice core [Johnsen et al., 1992]. Finally, the age of Termination II is taken from the U-Th dating of coral terraces [Bard et al., 1990; Stein et al., 1993].

\subsection{Tuning Target}

[21] Our tuning target is a simple nonlinear model of ice volume, $y$, which follows the equation

$$
\frac{d y}{d t}=\frac{1 \pm b}{T_{m}}(x-y)
$$

where the nonlinearity coefficient $b$ is subtracted during ice growth and added during ice decay [Imbrie and Imbrie, 1980]. The model's forcing function, $x$, is the 21 June insolation curve for $65^{\circ} \mathrm{N}$ from the La93 $(1,1)$ orbital solution, which uses modern values of dynamical ellipticity and tidal dissipation [Laskar et al., 1993]. We allow the nonlinearity $b$ and mean time constant $T_{m}$ of the ice model to increase with time due to the long-term increase in global ice volume. From $5.3-3.0 \mathrm{Ma}, b$ is 0.3 and $T_{m}$ is $5 \mathrm{kyr}$ (M. Mudelsee, personal communication, 2004). Both increase linearly to 0.6 and $15 \mathrm{kyr}$, respectively, by $1.5 \mathrm{Ma}$ and remain at those values to the present. The Pleistocene value of $b$ is taken from Imbrie and Imbrie [1980] while the time constant of $15 \mathrm{kyr}$ is selected to maximize agreement with the independent age estimates used for the last $135 \mathrm{kyr}$ of the stack.

[22] Ice sheet response time and the lag between insolative forcing and $\delta^{18} \mathrm{O}$ are poorly constrained before $0.8 \mathrm{Ma}$. We assume that small ice sheets respond more quickly than the massive ones of the late Pleistocene and choose early Pliocene values of $b$ and $T_{m}$ to reflect the absence of large northern hemisphere ice sheets. However, a study of the lag between $\delta^{18} \mathrm{O}$ and other climate proxies at ODP Site 662 suggests that $T_{m}$ may have been $\sim 15 \mathrm{kyr}$ since $3 \mathrm{Ma}$ (P. deMenocal, manuscript in preparation, 2005). Using a response time of $5 \mathrm{kyr}$, instead of $15 \mathrm{kyr}$, makes the early Pliocene portion of the LR0 4 age model $\sim 3$ kyr older. At the other extreme, if $T_{m}$ does not reach $15 \mathrm{kyr}$ until the late Pleistocene, our age estimates would be reduced by less than 1 kyr from 3.0-0.8 Ma.

[23] The largest uncertainty in the Pliocene portion of the LR04 age model probably comes from the orbital calculations themselves. Different values of tidal dissipation in the orbital solution can shift the age model by $5 \mathrm{kyr}$ at $5 \mathrm{Ma}$ [Laskar et al., 1993]. Additionally, changes in global ice volume could alter the Earth's dynamical ellipticity to produce age model errors of up to $20 \mathrm{kyr}$ by $5 \mathrm{Ma}$ [Laskar et al., 1993]. However, Lourens et al. [1996] do not find evidence for tidal dissipation or dynamical ellipticity changes in the Pliocene-Pleistocene climate record.

\subsection{Sedimentation Rate Constraints}

[24] To prevent tuning errors we monitor the implied average sedimentation rate of the stack throughout the tuning process. We construct two different estimates of global sedimentation rates: an LSR stack, which averages the sites' sedimentation rates, and a "normalized" LSR stack, which compensates for different mean sedimentation rates (MSR) across sites. The LSR of each site is calculated by placing its $\delta^{18} \mathrm{O}$ record on the stack's timescale and calculating its sedimentation rate. We calculate sedimentation rates as a function of meters composite depth (mcd) or revised mcd where possible ( $\sim 75 \%$ of ODP records) and as meters below seafloor (mbsf) otherwise. The first LSR stack is an average of all site's LSR estimates, interpolated to a 


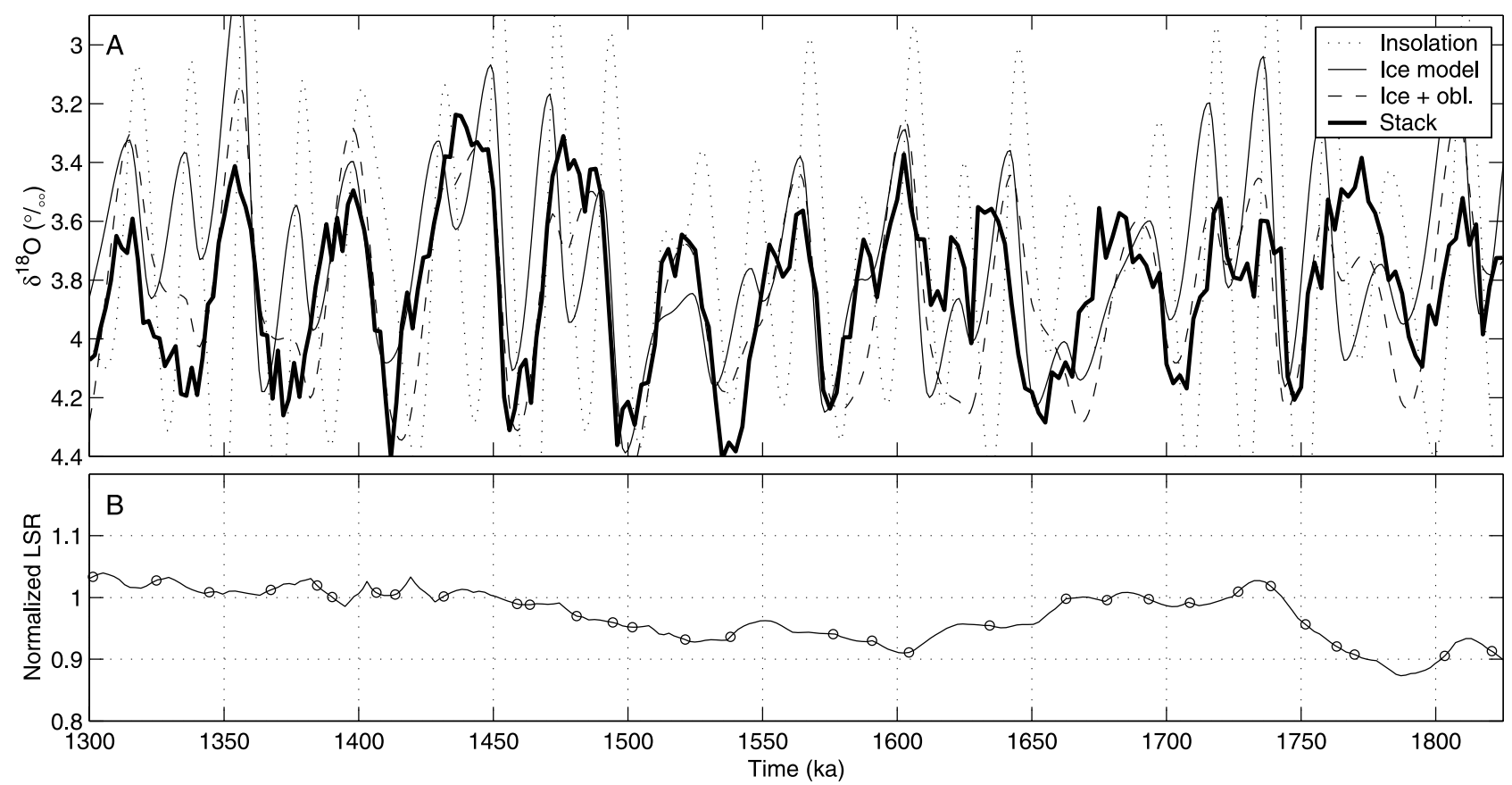

Figure 5. The tuning process. (a) The $\delta^{18} \mathrm{O}$ stack shown with 21 June insolation at $65^{\circ} \mathrm{N}$, the ice-model tuning target, and an equally weighted average of ice and obliquity. (b) The normalized LSR stack for the same time period with circles denoting age control points.

resolution of $2 \mathrm{kyr}$. The second, normalized LSR stack is constructed by dividing each site's LSR by its MSR prior to stacking. For the eleven sites with $\delta^{18} \mathrm{O}$ records aligned to the stack in multiple segments, the LSR of each segment is normalized separately. Normalization prevents sites with high MSRs from being unduly weighted and reduces the effect of records with different MSRs beginning and ending within the stack. For the idealized case in which each LSR is generated by an independent, stationary random process, the normalized LSR stack for the "true" age model would converge to a constant value of unity.

\subsection{Tuning}

[25] The LR04 stack is tuned to our simple ice model in a two-step process by the addition of age control points with an average spacing of $20 \mathrm{kyr}$. The goal of our first tuning is to find the correlation between $\delta^{18} \mathrm{O}$ and ice model minima which produces the least variation in stacked LSR. Because this initial age model is derived primarily from globally averaged sedimentation rates with minimal orbital tuning, we avoid assumptions about the age or length of each glacial cycle. We also allow the instantaneous phase of $\delta^{18} \mathrm{O}$ to lag insolation by $0-120^{\circ}$. This age model generates a normalized LSR stack with a standard deviation of only 0.06. In our second tuning we loosen the LSR constraint in order to keep the $\delta^{18} \mathrm{O}$ signal approximately in phase with the obliquity component of the ice model. Figure 5 shows the early Pleistocene portion of the stack and illustrates the balance achieved between strictly tuning the stack and minimizing the variance of normalized LSR.

[26] We emphasize obliquity in our tuning because its effect on insolation is symmetric across hemispheres and because obliquity induces the strongest $\delta^{18} \mathrm{O}$ response for most of the last 5.3 Myr. Our ice-model tuning target, which inherently accentuates the effects of obliquity relative to precession due to its long time constant, produces a fairly good match to the $\delta^{18} \mathrm{O}$ stack. However, averaging normalized versions of the ice model and lagged orbital obliquity produces a curve which often has an even better correlation to $\delta^{18} \mathrm{O}$ (e.g., in Figure 5). At the few points where correlation between the stack and the ice model is ambiguous within the constraints of average LSR, we choose the correlation which is most consistent with obliquity forcing. Section 7.1 provides uncertainty estimates for the LR04 age model.

[27] Figure 6 shows the stacks of true and normalized LSR produced by the final LR04 age model. Some features of the two stacks differ slightly because they weight the LSR of each site differently. For example, the LSR stack is more sensitive to variability at sites with high mean sedimentation rates while the normalized LSR stack is more sensitive to sites with low sedimentation rates. The normalized stack, in which each LSR record is divided by its mean sedimentation rate, has a standard deviation of 0.09 in the final LR04 age model. The normalized LSR stack generally varies by less than $10 \%$ from $4.3-0.1 \mathrm{Ma}$, demonstrating that little tuning is necessary to achieve a high coherence with obliquity. Prior to 4.3 Ma normalized LSR must vary by up to $\sim 20 \%$ in order to achieve coherence with obliquity. These larger deviations may occur because fewer records contribute to the stack before $4 \mathrm{Ma}$, because the average LSR of these sites is smaller, or because sedimentation rates experienced greater variability in the early Pliocene. The age models of Shackleton et al. [1995b] (hereinafter referred 

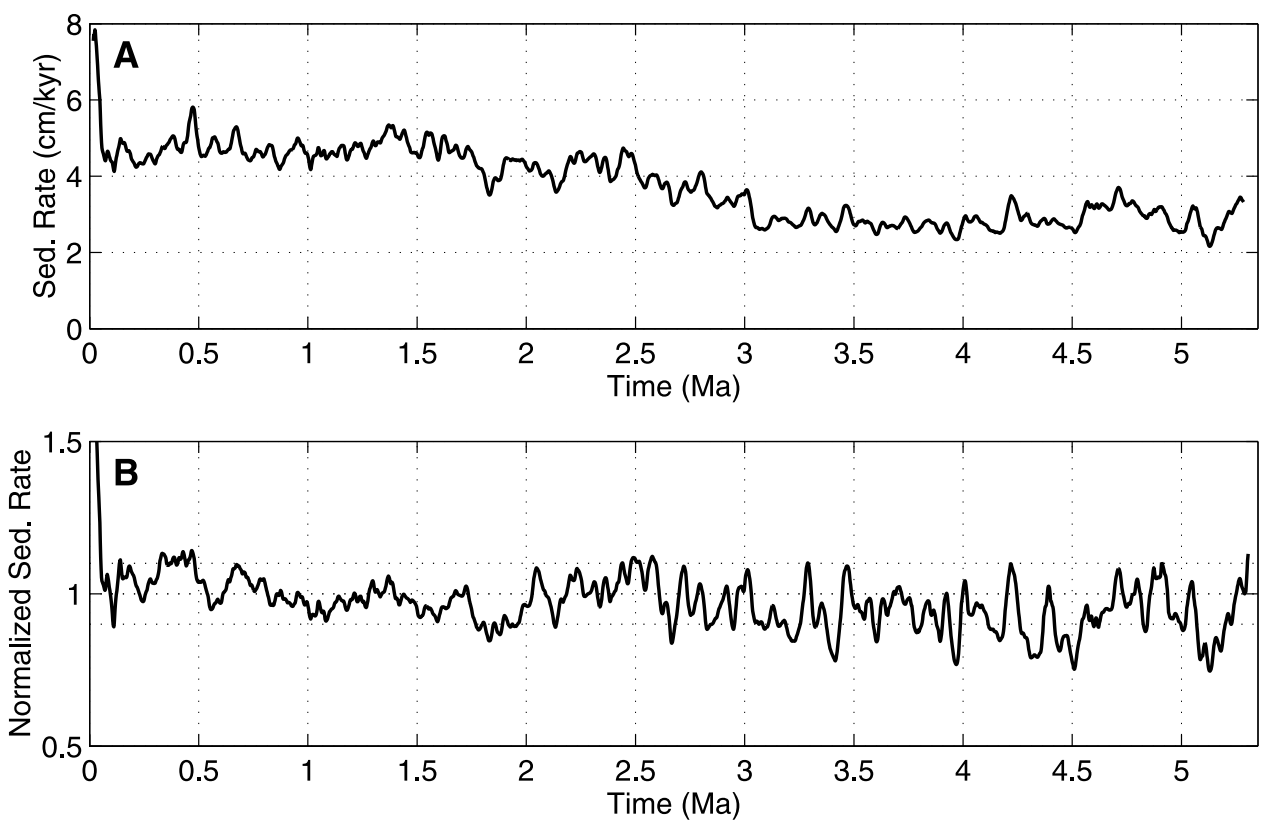

Figure 6. Average sedimentation rate for all sites, smoothed with a 30-kyr box car filter. (a) LSR stack and (b) normalized LSR stack with horizontal dotted lines at 0.9, 1.0, and 1.1.

to as SCHPS95) and Cande and Kent [1995] (hereinafter referred to as CK95) also result in higher LSR variability before $4.3 \mathrm{Ma}$.

[28] The coherence and phase of the stack relative to the obliquity and precession components of 21 June insolation are calculated using Blackman-Tukey cross-spectral analysis [Jenkins and Watts, 1968] with a moving window of $500 \mathrm{kyr}$ and a 300-kyr lag (Figure 7). The stack is generally incoherent with respect to the eccentricity component of insolation, but coherence with the obliquity component is at the $95 \%$ confidence level for most of its length and is always above the $80 \%$ confidence level. At least one precession frequency is coherent for all of the last $1.7 \mathrm{Myr}$ and most of the interval from 4.1-2.8 Ma.

[29] Because we emphasize obliquity in our tuning process, its phase relative to insolation is primarily determined by the lag generated by our ice model. The plot of obliquity phase in Figure 7 clearly shows the increase in model response time from $3.0-1.5 \mathrm{Ma}$. The lag in obliquity is relatively constant at $30^{\circ}(3.4 \mathrm{kyr})$ before $3 \mathrm{Ma}$, then increases steadily, and finally levels off at $60^{\circ}(6.8 \mathrm{kyr})$ in the Pleistocene. At 4.4 Ma the obliquity phase shows a small deviation, which may be related to the particularly low 41-kyr variance of $\delta^{18} \mathrm{O}$ at that time. The lag relative to precession is more variable. The average precession lag is $52^{\circ}$ (3.3 kyr) from 4.1-2.7 Ma, decreases to $21^{\circ}$ (1.3 kyr) from $2.7-1.6 \mathrm{Ma}$, and then jumps to $75^{\circ}$ (4.8 kyr) for the rest of the Pleistocene. The average error in coherent phase estimates is $8^{\circ}$ for $41 \mathrm{kyr}$ and $15^{\circ}$ for $23 \mathrm{kyr}$.

\section{Results}

\subsection{The $\delta^{18} \mathrm{O}$ Values}

[30] The LR04 benthic stack reconstructs the average $\delta^{18} \mathrm{O}$ signal of each marine isotope stage and substage within the Pliocene and Pleistocene. The features of these stages are largely independent of the assigned age model because the stack is constructed by graphic correlation. Overall, the mean standard error of the stack is $0.06 \%$, and only $2 \%$ of the data points have errors greater than $0.1 \%$. This paper presents all isotopic error bars as plus or minus two standard errors. The maximum $\delta^{18} \mathrm{O}$ value of the benthic stack is $5.08 \pm 0.11 \%$ at 433 and $630 \mathrm{ka}$ (MIS 12 and 16), and the minimum is $2.65 \pm 0.15 \%$ at $5.135 \mathrm{Ma}$ (MIS T7). The magnitudes and ages of the last seven glacial terminations are provided in Table 3 . We define termination magnitude as the difference between the maximum $\delta^{18} \mathrm{O}$ value of the preceding glacial and the minimum of the following interglacial. Each termination is dated by the temporal midpoint between the start and end of rapid change in $\delta^{18} \mathrm{O}$. Terminations III and VI are shown to be significantly smaller than the others, in agreement with Raymo [1997].

[31] Recent research has focused on MIS 11 as a possible analog for the present interglacial [e.g., Loutre and Berger, 2003; EPICA Community Members, 2004] because both occur during times of low eccentricity. The LR04 age model establishes that MIS 11 spans two precession cycles, with $\delta^{18} \mathrm{O}$ values below $3.6 \%$ for $20 \mathrm{kyr}$, from $398-418 \mathrm{ka}$. In comparison, stages 9 and 5 remained below 3.6\% for 13 and $12 \mathrm{kyr}$, respectively, and the Holocene interglacial has lasted 11 kyr so far. In the LR04 age model, the average LSR of 29 sites is the same from $398-418 \mathrm{ka}$ as from $250-$ $650 \mathrm{ka}$; consequently, stage 11 is unlikely to be artificially stretched. However, the 21 June insolation minimum at $65^{\circ} \mathrm{N}$ during MIS 11 is only $489 \mathrm{~W} / \mathrm{m}^{2}$, much less pronounced than the present minimum of $474 \mathrm{~W} / \mathrm{m}^{2}$. In addition, current insolation values are not predicted to return to the high values of late MIS 11 for another $65 \mathrm{kyr}$. We propose that this effectively precludes a "double precession 

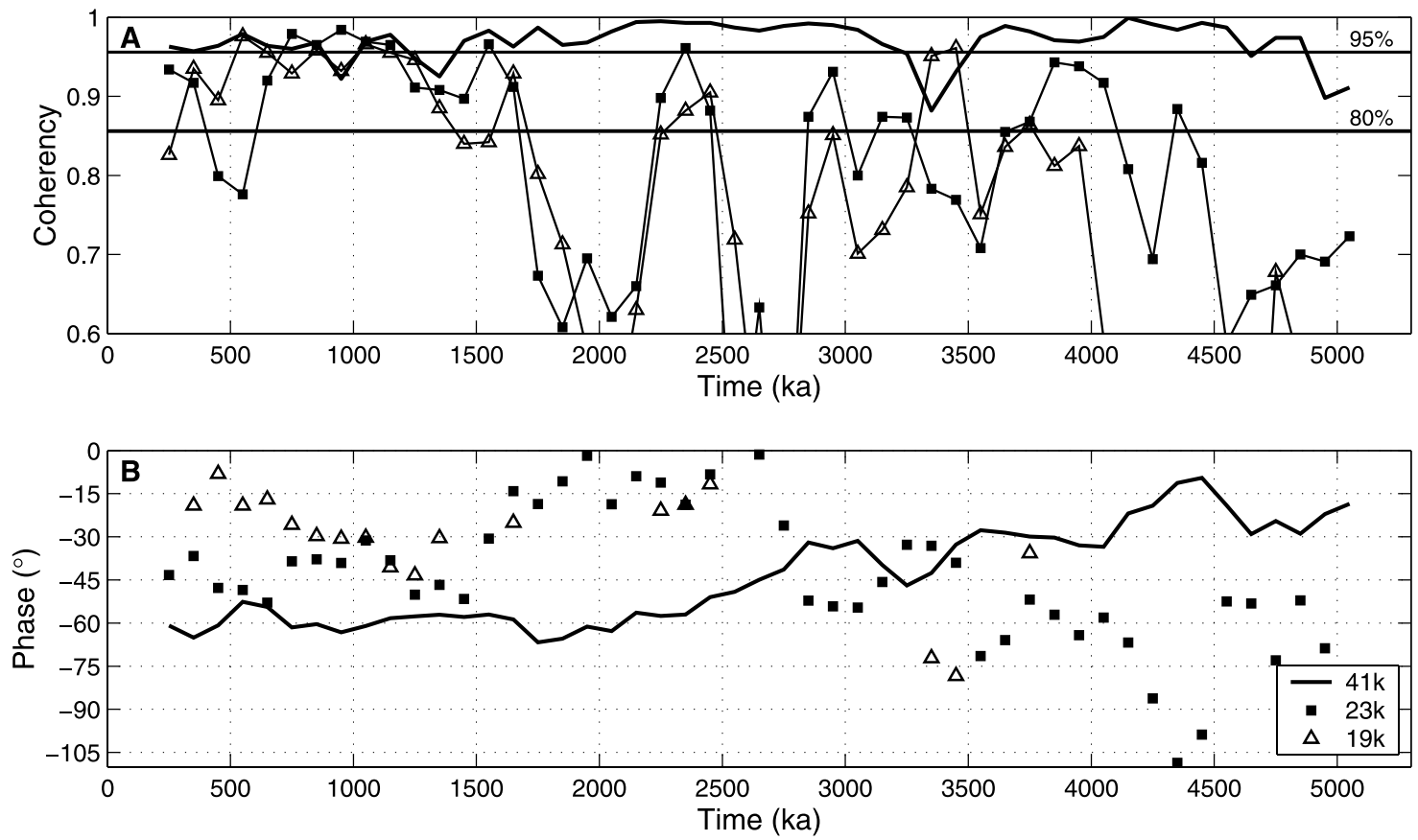

Figure 7. Cross-spectral relationships between the LR04 benthic stack and 21 June insolation at $65^{\circ} \mathrm{N}$. (a) Coherence with the 41-kyr (thick line), 23-kyr (squares), and 19-kyr (triangles) components of insolation. (b) Phase relative to insolation at 41, 23, and 19 kyr. Phases at 19 kyr are plotted only where coherent at the $80 \%$ confidence level.

cycle" interglacial [e.g., Raymo, 1997] in the Holocene without human influence.

\subsection{MIS Identification}

[32] In Figure 4 we use the MIS taxonomy of SPECMAP, Ruddiman et al. [1989], and Raymo et al. [1989] from the present to MIS 104 in the Pliocene. Below MIS 104 we adopt the stage identification scheme of Shackleton et al. [1995a] (hereinafter referred to as SHP95). In this scheme isotope events are identified based on the magnetic subchron within which they are found. For example, Co2 is the uppermost glacial excursion within the Cochiti subchron. Shackleton et al. [1995a] developed this methodology to prevent uncertainty in stage identifications from accumulating down core. While they suggest that further subdivisions of the stages be designated by lettered substages analogous to $5 \mathrm{a}-5 \mathrm{e}$ in the late Pleistocene, we feel that renumbering is less cumbersome and is justified by the large number of records examined in this study. Therefore we propose modifications to the early Pliocene MIS taxonomy as described below. Recognizing the potential for confusion when isotope stages are renamed, we do not remove any previously defined stages and only add a new one if it is clearly identifiable in most $\delta^{18} \mathrm{O}$ records and has an amplitude comparable to other nearby stages. Additionally, the flexibility of the SHP95 numbering scheme minimizes the number of renamed stages because new stages in one magnetic subchron will not alter MIS names in other subchrons.

[33] Above the Mammoth subchron, the stages in the LR04 stack are easily correlated to previous $\delta^{18} \mathrm{O}$ records (e.g., Sites 607 and 846) although many are better resolved by the stack. In the Pleistocene, the signal-to-noise ratio of $\delta^{18} \mathrm{O}$ is sufficiently high that most isotopic stages and substages are accurately recorded in individual sediment cores. One exception is the warm substage of MIS 28, which is quite clear in the LR04 stack but absent in the S95 composite and somewhat distorted in DSDP Site 607. The lower signal-to-noise ratio of the Pliocene makes the definition of MIS stages from a single core more difficult. Some of the smaller Pliocene stages from Sites 607 and 846 become better defined in the stack (e.g., MIS 77 and 83) while others almost disappear because they are small or absent in most $\delta^{18} \mathrm{O}$ records. The stages which are unusually small or poorly defined in the LR04 stack are MIS 68, 69, 79, 80, 94, 102, G5, G8, G9, K2, and KM6.

[34] Below the Mammoth subchron, the LR04 stack reduces noise in some portions of the record to the extent that new isotopic stages can be resolved. Therefore we introduce a new set of MIS names for these subchrons based on the identification of each stage in at least $80 \%$ of

Table 3. Recent Glacial Terminations

\begin{tabular}{ccc}
\hline Termination & Magnitude, \% & Age, ka \\
\hline I & $1.78 \pm 0.10$ & 14 \\
II & $1.86 \pm 0.13$ & 130 \\
III & $1.18 \pm 0.16$ & 243 \\
IV & $1.64 \pm 0.13$ & 337 \\
V & $1.97 \pm 0.12$ & 424 \\
VI & $1.15 \pm 0.14$ & 533 \\
VII & $1.57 \pm 0.15$ & 621 \\
\hline
\end{tabular}




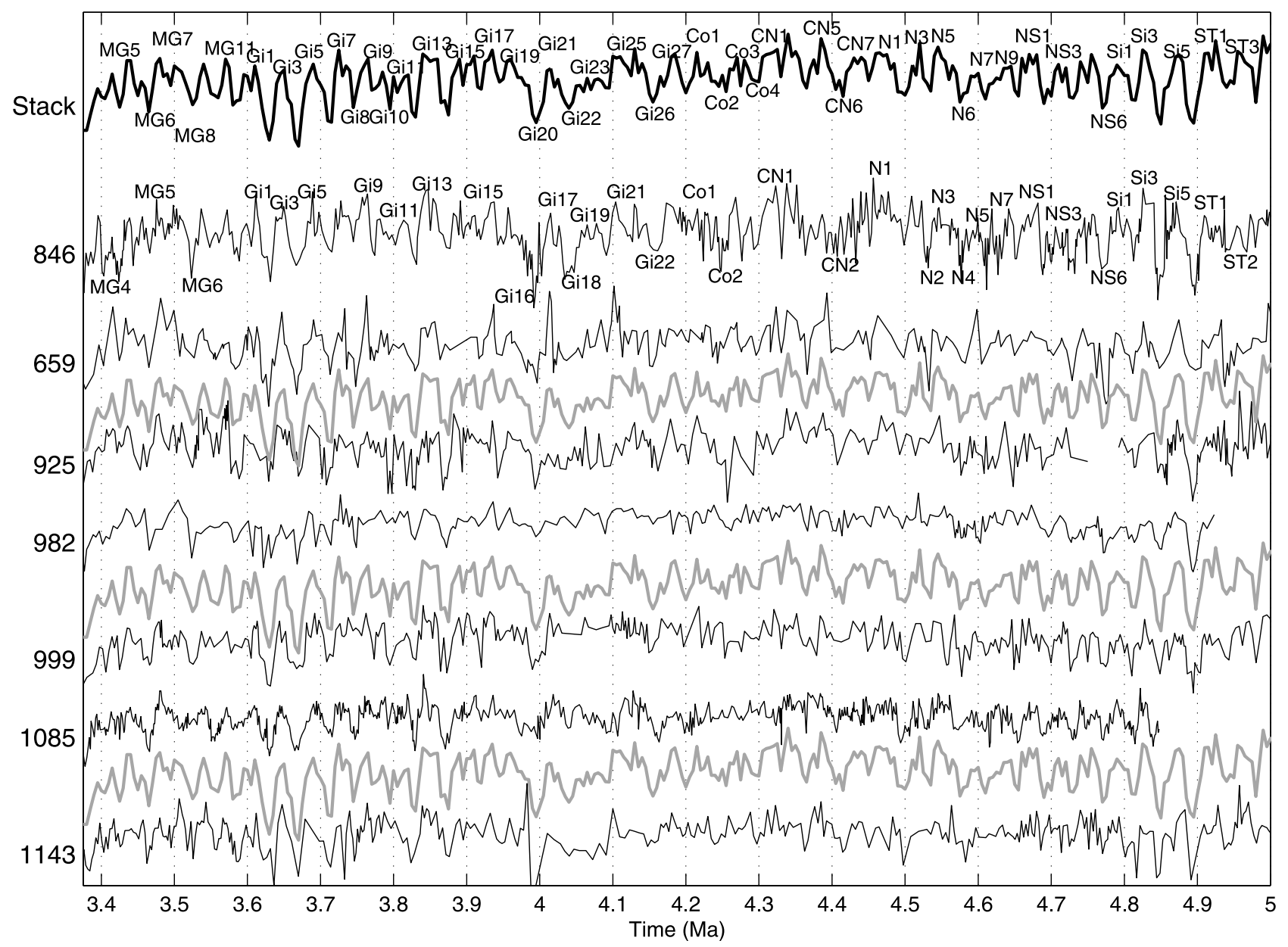

Figure 8. New Pliocene marine isotope stages. The LR04 stack (top and repeated as shaded line) and seven of the highest-resolution records aligned to the stack. Site 846 is labeled with SHP95 stage identifications.

the high-resolution records which span it. These new stages, which fall between MG5 and ST4, are shown in Figure 8 along with the SHP95 stage identifications of Site 846 and six other high-resolution benthic records. Each proposed change to the SHP95 stage names is described below. First, SHP95 stages MG5 and MG6 at the bottom of the Mammoth-Gauss interval are subdivided into stages MG5-MG12, as shown in Figure 8. Next, SHP95 stage Gi15 is subdivided into stages Gi15-Gi19, causing SHP95 stages Gi16-Gi22 to be renamed Gi20-Gi26. SHP95 stage N1 is split into stages N1-N3, and SHP95 stages $\mathrm{N} 2-\mathrm{N} 8$ are renamed N4-N10. Finally, we insert stages Gi27-Gi28, Co3-Co4, CN3-CN8, and ST3-ST4 at the bottoms of their respective subchrons, where they have no effect on subsequent stage names. From the Thvera subchron down, we again adopt the stage names of SHP95.

\subsection{Paleomagnetic Polarity Reversals}

[35] In Table 4 we compare the age estimates of paleomagnetic polarity reversals from Shackleton et al. [1990] (hereinafter referred to as SBP90), SCHPS95, CK95, Lourens et al. [1996], and the LR04 age model. Errors in these estimates can arise from both age model construction and reversal identification within sediment cores. Therefore we estimate the ages of magnetic reversals down to the Matuyama/Gauss boundary according to their average ages in Sites 607, 659, 677, 982, 983, 1090, 1146, and 1148, with outliers more than $2 \%$ away from the mean removed. The standard deviation in reversal ages from these sites ranges from 5 to $22 \mathrm{kyr}$. Because fewer records are available, below the Matuyama we also use reversal identifications from Leg 138, correlated to Site 846 [Shackleton et al., 1995b]. Ages for the Kaena and Mammoth subchrons are averages from Sites 607 and 846 while the Gauss/Gilbert boundary and the top of the Cochiti subchron are dated from Sites 659 and 846. All other polarity reversals are based solely on Site 846. Given the error involved in reversal identification, we observe that all four age models are quite similar.

\subsection{Comparison to $\mathbf{S 9 5}$ Composite}

[36] With a few exceptions, the LR04 global PliocenePleistocene stack is similar to the S95 composite, which contains unstacked, high-resolution benthic records from sites V19-30, ODP 677, and ODP 846. One difference between the two records is that the S95 composite is $\sim 0.14 \%$ o heavier than the LR04 stack after $1.8 \mathrm{Ma}$, where 
Table 4. Magnetic Polarity Reversal Ages, Ma

\begin{tabular}{lccccc}
\hline \multicolumn{1}{c}{ Reversal $^{\text {a }}$} & MIS & $\begin{array}{c}\text { SBP90/ } \\
\text { SCHPS95 }\end{array}$ & CK95 & $\begin{array}{c}\text { Lourens et } \\
\text { al. [1996] }\end{array}$ & $\begin{array}{c}\text { LR04 } \\
\text { (This Study) }\end{array}$ \\
\hline Brunhes/Matuyama & 19 & 0.780 & 0.780 & & 0.780 \\
Jaramillo (t) & 28 & 0.990 & 0.990 & & 0.991 \\
Jaramillo (b) & 31 & 1.070 & 1.070 & & 1.075 \\
Olduvai (t) & 63 & 1.770 & 1.770 & 1.785 & 1.781 \\
Olduvai (b) & 74 & 1.950 & 1.950 & 1.942 & 1.968 \\
Matuyama/Gauss & G2 & 2.600 & 2.581 & 2.582 & 2.608 \\
Kaena (t) & G22 & 3.046 & 3.040 & 3.032 & 3.045 \\
Kaena (b) & KM2 & 3.131 & 3.110 & 3.116 & 3.127 \\
Mammoth (t) & KM6 & 3.233 & 3.220 & 3.207 & 3.210 \\
Mammoth (b) & MG1 & 3.331 & 3.330 & 3.330 & 3.319 \\
Gauss/Gilbert & MG12 & 3.594 & 3.580 & 3.596 & 3.588 \\
Cochiti (t) & Gi27 & 4.199 & 4.180 & 4.188 & 4.184 \\
Cochiti (b) & Co4 & 4.316 & 4.290 & 4.300 & 4.306 \\
Nunivak (t) & N1 & 4.479 & 4.480 & 4.493 & 4.478 \\
Nunivak (b) & N9 & 4.623 & 4.620 & 4.632 & 4.642 \\
Sidufjall (t) & Si2 & 4.781 & 4.800 & 4.799 & 4.807 \\
Sidufjall (b) & Si6 & 4.878 & 4.890 & 4.896 & 4.898 \\
Thvera (t) & T1 & 4.977 & 4.980 & 4.998 & 4.989 \\
Thvera (b) & TG2 & 5.232 & 5.230 & 5.236 & 5.254 \\
\hline
\end{tabular}

${ }^{\mathrm{a}}$ Here t, top; b, bottom.

the 677 and 846 records are joined. This suggests that sites V19-30 and 677 have a small offset in $\delta^{18} \mathrm{O}$ relative to the global mean. Additionally, the higher signal-to-noise ratio of the LR04 stack allows us to resolve new isotopic stages in the early Pliocene, as detailed above. Other discrepancies between the two records are confined to the magnitudes of specific isotopic stages. For example, the $\mathrm{S} 95$ composite underestimates the magnitude of Termination $\mathrm{V}$ by $0.6 \%$, and the S95 composite records a pair of large positive excursions in $\delta^{18} \mathrm{O}$ at $3.35 \mathrm{Ma}$ (MIS M2 and MG2) where the LR04 stack shows only one. Figure 9 demonstrates that ODP Site 846 is the only record in the stack to contain both large glacial excursions, suggesting a possible coring or splicing error. Also, the magnitudes of the heavy glacial stages KM2, Gi20, and Gi22 in the LR04 stack are 0.3\%o smaller than at Site 846.

[37] The age model of the S95 composite is based on the correlation of percent carbonate to orbital data. The portion from Site 677 is tuned to an ice model [Shackleton et al., 1990], and the portion from Site 846 is tuned directly to summer insolation with no phase lag [Shackleton et al., 1995b]. Although based on different tuning rationales, the LR04 and S95 age models differ by less than $\sim 10 \mathrm{kyr}$ with only two exceptions. From 400-590 ka the S95 composite is as much as $20 \mathrm{kyr}$ younger than the LR04 and SPECMAP stacks (Figure 10). The EDC2 timescale for the ice core from Dome C, Antarctica [EPICA Community Members, 2004], which is based on a parameterized ice-flow model, presents age estimates similar to the S95 composite for MIS 13 and 14 but is nearly identical to the LR04 age model at MIS 11. On the basis of the average sedimentation rates of over 30 marine sediment records, we propose that the MIS 13 and 14 age estimates of the S95 composite and EDC2 are in error. Either would require a short-term increase in global sedimentation rates of about $70 \%$, a fluctuation which is three times larger than any other in the last $5.3 \mathrm{Myr}$ (except for the effects of uncompacted sediments from $0-50 \mathrm{ka}$ ). Because the EDC2 timescale is otherwise in close agreement with ours, the misalignment of stages 13 and 14 may indicate a stratigraphic disturbance in the ice core at the top of MIS 15.

[38] From 1.8-4.0 Ma the S95 composite is on average $7 \mathrm{kyr}$ older than the LR04 age model, primarily due to the different phase lag assumptions used. Before 4.5 Ma the S95 composite is $\sim 20 \mathrm{kyr}$ younger than our age model (see Table 4) due to the use of the Berger and Loutre [1991] astronomical solution in the work of Shackleton et al. [1995b]. The LR04 age model agrees with the work of Lourens et al. [1996], which concludes that the S95 timescale is one obliquity cycle too young prior to $\sim 4.6 \mathrm{Ma}$, based on the better fit of the geologic record to the Laskar et al. [1993] orbital solution.

\subsection{Comparison to Other Stacks}

[39] The LR04 benthic stack is generally similar to previously published stacks with respect to MIS features and timescale but differs somewhat in its variance and spectral density. Table 5 gives a summary of total and orbital-band variances for the late Pleistocene from the five $\delta^{18} \mathrm{O}$ stacks discussed in this paper. We perform BlackmanTukey spectral analysis for $0-780 \mathrm{ka}$ with a lag of $400 \mathrm{kyr}$. (SPECMAP is analyzed over only the last $625 \mathrm{kyr}$ with a 350-kyr lag.) The LR04 stack has more total variance than any of the other stacks but also contains proportionally more sites from the Atlantic, which may increase the amplitude of its deep-water temperature signal. When only deep Pacific sites are stacked, the variance decreases to $0.16 \% 0^{2}$. This is comparable to the variance of the S95 composite, which represents one Pacific site, but still larger than the stacks of SPECMAP and Karner et al. [2002], suggesting that their

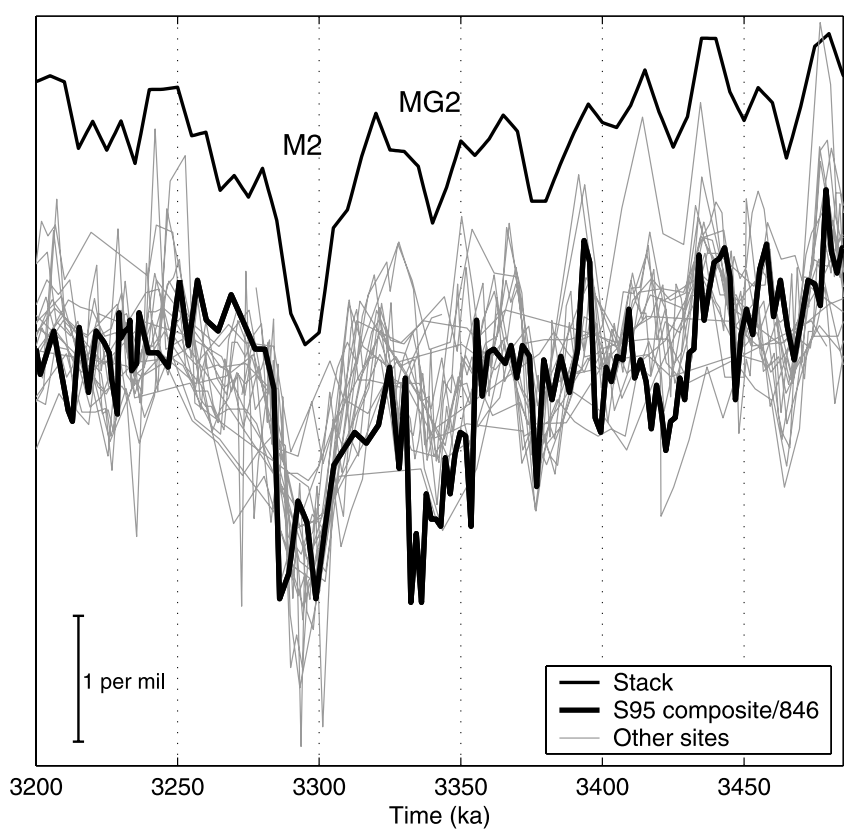

Figure 9. Marine isotope stages M2 and MG2. (top) The LR04 stack shows a small MG2 glacial stage. Of the (bottom) $19 \delta^{18} \mathrm{O}$ records spanning stages $\mathrm{M} 2$ and MG2, only ODP Site 846 (thick line) shows a particularly heavy glacial at MG2. All lower curves have been aligned vertically for illustrative purposes. 

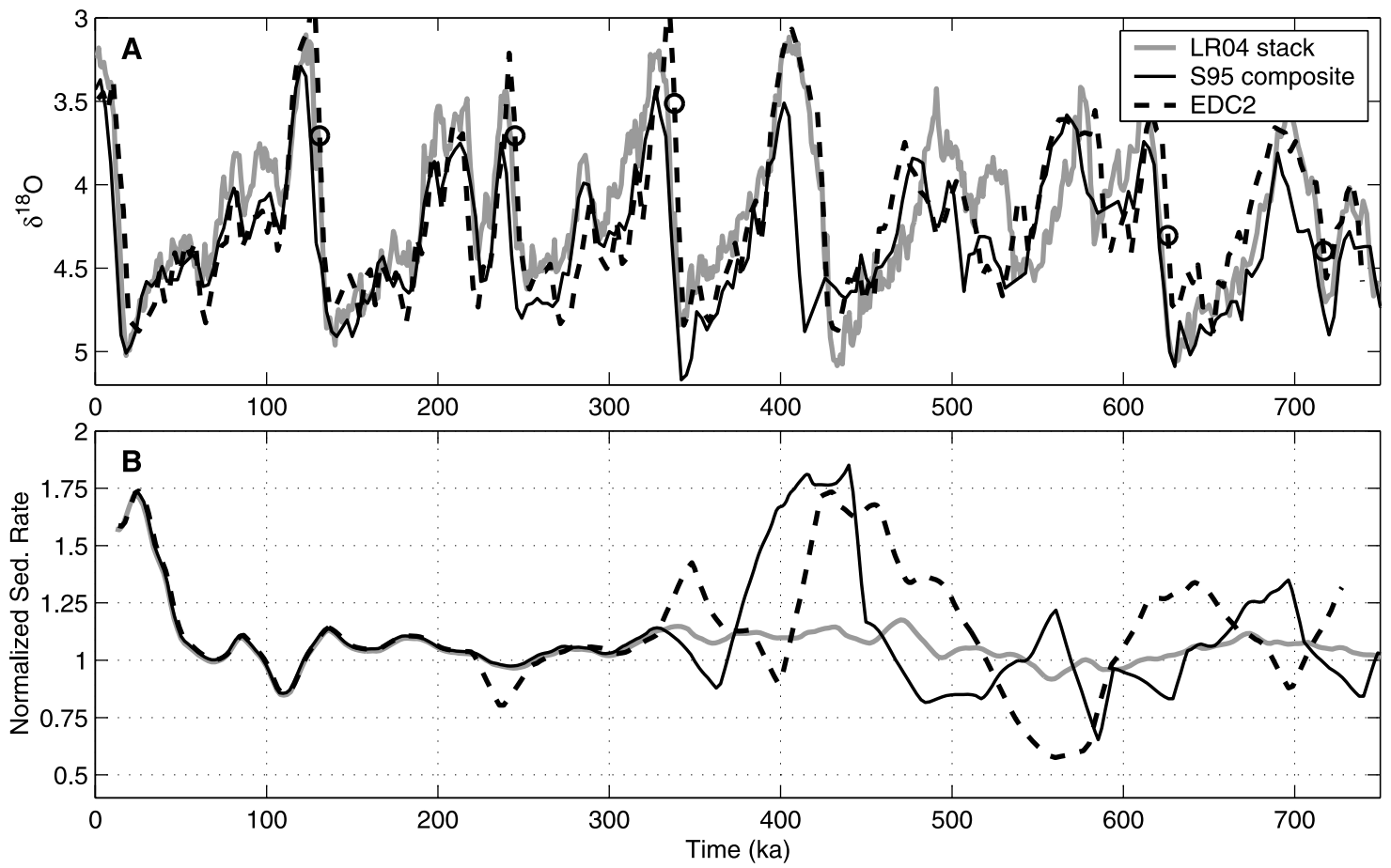

Figure 10. (a) Late Pleistocene age models of the LR04 stack, the S95 composite, and the EDC Antarctic ice core (rescaled ice $\delta \mathrm{D}, \mathrm{EDC} 2$ age model) [EPICA Community Members, 2004]. Circles mark age control points used to parameterize the EDC2 ice-flow model. (b) The average normalized sedimentation rates (defined in section 5.3) produced by each age model.

stacking techniques fail to preserve the full amplitude of late Pleistocene $\delta^{18} \mathrm{O}$ change.

[40] The MIS features of the LR04 and SPECMAP stacks are quite similar back to $625 \mathrm{ka}$, but the planktonic SPECMAP stack has relatively more variance in the eccentricity and precession bands and less in obliquity, possibly due to precessional responses in sea-surface conditions. The variance of the SPECMAP stack is only $60 \%$ that of the LR04 stack from $0-625 \mathrm{ka}$. The low resolution of SPECMAP records and the smoothing performed on the final stack probably played a large role in reducing SPECMAP variance. The SPECMAP and LR04 age models typically differ by less than $6 \mathrm{kyr}$ since $625 \mathrm{ka}$ (Figure 11). The SPECMAP age model is distorted before $625 \mathrm{ka}$ due to an error in the accepted age of the Brunhes/Matuyama reversal, later corrected by Shackleton et al. [1990].

[41] Karner et al. [2002] present a "minimally tuned" stack of six tropical benthic $\delta^{18} \mathrm{O}$ records extending to
$860 \mathrm{ka}$. Before stacking they tune the obliquity component of each record and apply a phase offset to produce a core-top age of 0 kyr. Unlike the development of our age model, their tuning requires initial age estimates to calculate the 41-kyr component of each record. This step produces alignment errors which cause the authors to create a second stack that excludes records with highly variable sedimentation rates. This second, tropical stack has consistently less amplitude than ours and a mean standard error of $0.09 \%$ (compared to $0.05 \%$ for the LR04 stack over the same interval). The reduced amplitude of their stack is probably due to the introduction of phase shifts between its component $\delta^{18} \mathrm{O}$ records. Phase differences of up to $11 \mathrm{kyr}$ between their $\delta^{18} \mathrm{O}$ records can be expected to reduce their stack's precession component in particular. Indeed, the tropical stack has only $25 \%$ as much precessional variance as the LR04 stack (Table 5). The Karner et al. [2002] and LR04 age models generally differ by 3-13 kyr, converging only at 0 and

Table 5. Orbital Variance in $\delta^{18} \mathrm{O}, 0-780 \mathrm{ka}$

\begin{tabular}{lccccc}
\hline & LR04 $^{\mathrm{a}}$ & S95 & SPECMAP $^{\mathrm{b}}$ & Tropical Stack $^{\mathrm{c}}$ & HW04 $^{\mathrm{d}}$ \\
\hline Total Variance, $\%{ }^{2}$ & 0.20 & 0.15 & 0.12 & 0.13 & - \\
Eccentricity (88-120 kyr), \% & 45 & 37 & 48 & 54 & 52 \\
Obliquity (38-48 kyr), \% & 18 & 17 & 12 & 2.6 & 12 \\
Precession (17-25 kyr), \% & 6.7 & 9.2 & 13 & & \\
\hline${ }^{\mathrm{a}}$ This study. & & & & \\
${ }^{\mathrm{b}}$ From 0 to 625 ka. & & & & \\
$\quad{ }^{\mathrm{c}}$ From Karner et al. [2002]. & & &
\end{tabular}




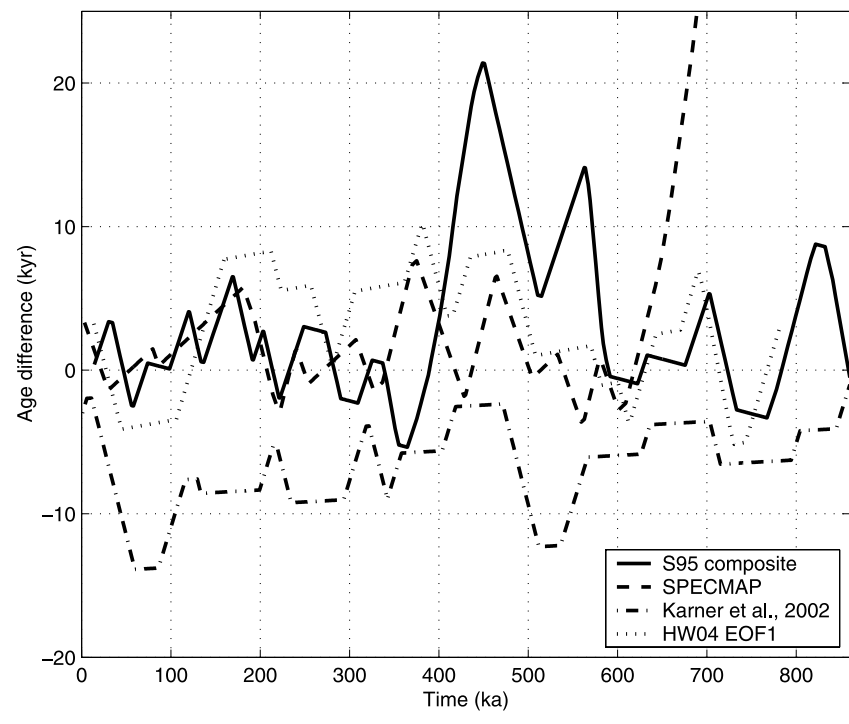

Figure 11. Differences between the LR04 age model and four other $\delta^{18} \mathrm{O}$ age models. Positive values indicate that isotopic features are older in the LR04 age model.

$860 \mathrm{ka}$. However, the lower precession power of the tropical stack (Figure 12) is not caused by age model differences because using the LR04 age model only increases the tropical stack's precession power to $2.8 \%$ of total variance.

[42] The depth-derived age model of Huybers and Wunsch [2004] ranges from $5 \mathrm{kyr}$ older to $8 \mathrm{kyr}$ younger than the LR04 age model and averages $6.5 \mathrm{kyr}$ younger from $150-500 \mathrm{ka}$. These age differences all fall within the uncertainty estimates published for the HW04 age model. The leading EOF of their best benthic and planktonic records contains proportionally more variance than the LR04 stack in the 100-kyr band but less in the 41- and 23-kyr bands. Huybers and Wunsch [2004] predict this drop off in orbital variance at higher frequencies due to the effects of jitter in their age model. The spectral power and substage features of their EOF are also affected by the use of only 17 age control points to align the records. Interestingly, even their benthic EOF with no orbital tuning has more variance in the precession band $(3.6 \%)$ than the minimally tuned stack of Karner et al. [2002].

\section{Discussion}

\subsection{Age Model Uncertainty}

[43] The greatest potential source of error in the LR04 age model is uncertainty in the orbital solution, which may be as high as $25 \mathrm{kyr}$ in the early Pliocene. Relative to the orbital solution, our tuning errors should be no more than a few thousand years because we tune a low-noise signal and avoid spikes in the stack's average sedimentation rate. The only portion of the timescale for which we consider tuning errors greater than $10 \mathrm{kyr}$ possible is prior to $4.3 \mathrm{Ma}$, where the stack contains less 41-kyr variance and larger deviations in average LSR are required to achieve coherence with obliquity. Before $5 \mathrm{Ma}$ the LR04 age model is also subject to increased uncertainty because the stack contains fewer records and inherently has fewer tuning and alignment constraints.

[44] In the more recent part of the age model, most of the uncertainty derives from our sedimentation rate constraint and the assumed response times of the ice sheets. The LSR tuning technique may neglect some real but highfrequency changes in global LSR, such as those resulting from global climate reorganizations over glacial-interglacial cycles. However, such changes would produce age model errors of no more than several thousand years, and alignment to the tuning target prevents these errors from accumulating over multiple cycles. Deviations from the tuning target due to our sedimentation rate constraints are typically no more than 4 kyr. Uncertainty in ice sheet response time could produce errors of $1 \mathrm{kyr}$ in the Pleistocene and $3.5 \mathrm{kyr}$ in the Pliocene. Including all sources of error, we estimate the uncertainty in the LR04 age model to be $40 \mathrm{kyr}$ from 5.3-5 Ma, $30 \mathrm{kyr}$ from 5-4 Ma, $15 \mathrm{kyr}$ from 4-3 Ma, $6 \mathrm{kyr}$ from 3-1 Ma, and 4 kyr from 1-0 Ma.

\subsection{Precession Phase and Deep-Water Temperature}

[45] As explained in section 5.4, the time constant of our ice model is the primary factor controlling the stack's phase relative to obliquity. Because we emphasize obliquity in our tuning procedure, the stack's phase relative to precession is allowed to deviate from that of the ice model. Indeed, Figure 7 shows that the stack's lag in precession actually decreases at $2.7 \mathrm{Ma}$ while the icesheet response time and obliquity lag begin to increase. From $2.7-1.6 \mathrm{Ma}$ the average precession lag is only $21^{\circ}$ or $1.3 \mathrm{kyr}$, about $2 \pm 1 \mathrm{kyr}$ smaller than that of our ice model tuning target. This small lag suggests that a

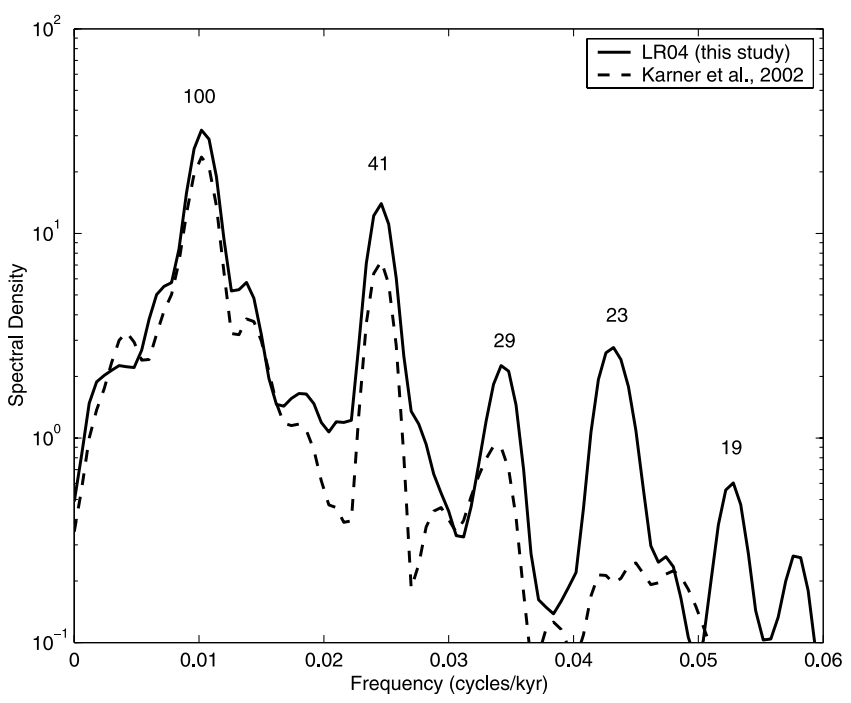

Figure 12. The spectral density of benthic $\delta^{18} \mathrm{O}$ over the last $860 \mathrm{kyr}$ in the LR04 stack (solid line) and the minimally tuned tropical stack of Karner et al. [2002] (dashed line). Spectral analysis is performed using Blackman-Tukey analysis with 500 lags on 860 values. (The peak at $29 \mathrm{kyr}$ is commonly observed and is thought to be a nonlinear climate response [e.g., Huybers and Wunsch, 2004].) 
significant portion of the precession component of late Pliocene $\delta^{18} \mathrm{O}$ is a deep-water temperature signal which leads ice volume. An increase in the magnitude of temperature response at $2.7 \mathrm{Ma}$ would account for the observed decline in precession lag during the onset of northern hemisphere glaciation. The temperature response may have continued to increase from 2.7-1.6 Ma, compensating for the gradually increasing lag of the ice model. At 1.6 Ma the precession lag suddenly jumps by $45^{\circ}$ relative to that of obliquity, putting it in close agreement with our ice model for the rest of the Pleistocene.

[46] Phase measurements are fairly sensitive to age model uncertainty, but this is not a likely explanation for this sudden phase shift. First, the stack's obliquity phase is approximately constant at 1.6 Ma. Changing the age model to eliminate the jump in precession lag would therefore produce a counterintuitive decline in obliquity lag. If the ice model's mean time constant $T_{m}$ is held constant at $15 \mathrm{kyr}$ for the last $3 \mathrm{Myr}$, a $30^{\circ}$ change in precession lag still occurs at 1.6 Ma. Finally, the use of an ice model forced by insolation on a day other than 21 June shifts the precession lag of the entire stack but does not affect the sudden change at $1.6 \mathrm{Ma}$.

[47] The observed increase in $\delta^{18} \mathrm{O}$ lag at $1.6 \mathrm{Ma}$ could be due to a decline in precession-driven temperature change, an increase in the precession response of ice volume, or an increase in the lag of temperature. We propose that either a climate feedback sensitive to precession enhanced ice sheet response or the deep-water temperature signal became phase-locked with ice volume due to the increased climatic influence of large northern hemisphere ice sheets. Additionally, a pronounced expansion of polar (cold water) fauna occurs in the North Atlantic at about this time [Raymo et al., 1986; Mc Intyre et al., 2001].

[48] Finally, the stack's coherence with precession from 4.1-2.8 Ma provides clues to the climate's response before the growth of major northern hemisphere ice. The stack's phase relative to precession in this interval demonstrates that northern hemisphere insolation was the major driver of benthic $\delta^{18} \mathrm{O}$ change by at least $4.1 \mathrm{Ma}$, perhaps through northern deep-water formation or the growth of small northern glaciers. Precession response is not significantly coherent prior to $4.1 \mathrm{Ma}$, presumably due to weaker $\delta^{18} \mathrm{O}$ response, but our phase estimates are still indicative of northern hemisphere forcing. We also note that the stack's precession lag prior to $3.6 \mathrm{Ma}$ is sensitive to the value of tidal dissipation in the orbital solution, producing an uncertainty of about $30^{\circ}$.

\section{Conclusions}

[49] The global Pliocene-Pleistocene stack presented in this paper contains benthic $\delta^{18} \mathrm{O}$ data from 57 globally distributed sites and has an average standard error of only $0.06 \%$. The LR0 4 age model takes advantage of the stack's low noise content and conservatively tunes the stack within the constraints provided by global sedimentation rates. The LR04 stack and the LR04 age model provide the paleoclimate community with two stratigraphic tools, which can be applied to a wide variety of Pliocene-Pleistocene studies. We hope that they will serve as a much-needed common timescale and reference of comparison (correlation target) for the large number of paleoceanographic records collected recently.

[50] The LR04 stack agrees well with previously published stacks for the late Pleistocene but exhibits significantly more variance as the result of higher-resolution records, a better alignment technique, and a greater percentage of records from the Atlantic. The LR04 stack is also the first stack to extend before $2.5 \mathrm{Ma}$ and therefore offers an invaluable improvement in signal quality for the early to mid-Pliocene. We define 24 new isotopic stages from 5.03.4 Ma and identify several likely errors in the S95 composite. The LR04 age model, designed to minimize changes in global sedimentation rates, generally supports the SPECMAP timescale back to $625 \mathrm{ka}$ and the S95 age model, except from 0.6-0.4 Ma and before 4.5 Ma. Finally, the LR04 stack's phase relative to precession suggests the presence of a large deep-water temperature signal from 2.71.6 Ma and reveals a sudden change in the phase of precession response at $1.6 \mathrm{Ma}$.

\section{Notation}

$x \quad 21$ June insolation at $65^{\circ} \mathrm{N}, \mathrm{W} / \mathrm{m}^{2}$;

$y$ modeled ice volume;

$b$ nonlinearity coefficient of ice;

$T_{m}$ mean time constant of ice, kyr;

$\sigma$ standard deviation.

[51] Acknowledgments. We thank all of the researchers who have made their data available; without their work, these results would not be possible. L. Lisiecki also thanks T. Herbert, W. Prell, and S. Clemens for their guidance throughout this project. We thank R. Tiedemann and L. Skinner for their thoughtful reviews. N. Shackleton, W. Ruddiman, P. deMenocal, Z. Liu, K. Lawrence, L. Cleaveland, P. Huybers, and M. Mudelsee also contributed many helpful comments regarding this manuscript.

\section{References}

Alley, R. B. (2003), Raising paleoceanography, Paleoceanography, 18(4), 1085, doi:10.1029/ 2003PA000942.

Andersson, C., D. A. Warnke, J. E. T. Channell, J. Stoner, and E. Jansen (2002), The midPliocene (4.2-2.6 Ma) benthic stable isotope record of the Southern Ocean: ODP Sites 1092 and 704, Meteor Rise, Palaeogeogr. Palaeoclimatol. Palaeoecol., 182, 165-181.

Bard, E., B. Hamelin, and R. G. Fairbanks (1990), $\mathrm{U}-\mathrm{Th}$ ages obtained by mass spectrometry in corals from Barbados: Sea level during the past 130,000 years, Nature, 346, 456-458.

Bassinot, F. C., L. D. Labeyrie, E. Vincent, X. Quidelleur, N. J. Shackleton, and Y. Lancelot (1994), The astronomical theory of climate and the age of the Brunhes-Matuyama magnetic reversal, Earth Planet. Sci. Lett., 126, 91-108.

Berger, W. H., and M. F. Loutre (1991), Insolation values for the climate of the last $10 \mathrm{~m}$. y., Quat. Sci. Rev., 10, 297-317.
Berger, W. H., T. Bickert, H. Schmidt, and G. Wefer (1993), Quaternary oxygen isotope record of pelagic foraminifers: Site 806, Ontong Java Plateau, Proc. Ocean Drill. Program Sci. Results, 130, 381395.

Bickert, T., and G. Wefer (1996), Late Quaternary deep water circulation in the South Atlantic: Reconstruction from carbonate dissolution and benthic stable isotopes, in The South Atlantic: Present and Past Circulation, edited 
by G. Wefer et al., pp. 599-620, Springer, New York

Bickert, T., W. B. Curry, and G. Wefer (1997), Late Pliocene to Holocene (2.6-0 Ma) western equatorial Atlantic deep-water circulation: Inferences from benthic stable isotopes, Proc. Ocean Drill. Program Sci. Results, 154, $239-$ 254.

Billups, K., A. C. Ravelo, and J. C. Zachos (1998), Early Pliocene deep water circulation in the western equatorial Atlantic: Implications for high-latitude climate change, Paleoceanography, 13, 84-95.

Broecker, W. S., E. Clark, I. Hajdas, and G. Bonani (2004), Glacial ventilation rates for the deep Pacific Ocean, Paleoceanography, 19, PA2002, doi:10.1029/2003PA000974.

Cande, S. C., and D. V. Kent (1995), Revised calibration of the geomagnetic polarity timescale for the Late Cretaceous and Cenozoic, J. Geophys. Res., 100(B4), 6093-6095.

Chen, J., J. Farrell, D. Murray, and W. Prell (1995), Timescale and paleoceanographic implications of a $3.6 \mathrm{~m}$. y. oxygen isotope record from the northeast Indian Ocean (Ocean Drilling Program site 758), Paleoceanography, 10, 21-47.

Clemens, S. C., D. W. Murray, and W. L. Prell (1996), Nonstationary phase of the PlioPleistocene Asian monsoon, Science, 274, 943-948.

Curry, W. B., and K. G. Miller (1989), Oxygen and carbon isotopic variation in Pliocene benthic foraminifers in, Proc. Ocean Drill. Program Sci. Results, 138, 157-166.

deMenocal, P. B., D. W. Oppo, R. G. Fairbanks, and W. L. Prell (1992), Pleistocene $\delta^{13} \mathrm{C}$ variability of North Atlantic intermediate water, Paleoceanography, 7, 229-250.

EPICA Community Members (2004), Eight glacial cycles from an Antarctic ice core, Nature, 429, 623-628.

Flower, B. P., D. W. Oppo, J. F. McManus, K. A. Venz, D. A. Hodell, and J. L. Cullen (2000) North Atlantic intermediate to deep water circulation and chemical stratification during the past $1 \mathrm{Myr}$, Paleoceanography, 15, $388-403$.

Franz, S.-O. (1999), Pliozäne Zeitreihen zur Rekonstruktion der Tiefenwasserzirkulation und der siliziklastischen Amazonasfracht im äquatorialen Westatlantik (Ceara Schwelle, ODP Leg 154), Rep. 84, Geomar, Kiel, Germany.

Grootes, P. M., M. Stuvier, J. W. C. White, S. J. Johnsen, and J. Jouzel (1993), Comparison of oxygen isotope records from GISP2 and GRIP Greenland ice cores, Nature, 366, 552-554.

Hale, W., and U. Pflaumann (1999), Sea-surface temperature estimations using a modern ana$\log$ technique with foraminiferal assemblages from western Atlantic Quaternary sediments, in Use of Proxies in PaleoceanographyExamples From the South Atlantic, edited by G. Fischer and G. Wefer, pp. 69-90, Springer, New York.

Hall, I. R., I. N. McCave, N. J. Shackleton, G. P. Weedon, and S. E. Harris (2001), Intensified deep Pacific inflow and ventilation in Pleistocene glacial times, Nature, 412, 809-812.

Harris, S. E. (2002), Data report: Late PliocenePleistocene carbon and oxygen stable isotopes from benthic foraminifers at Ocean Drilling Program Site 1123 in the southwest Pacific, Proc. Ocean Drill. Program Sci. Results, 181, 1-20. (Available at http://www-odp. tamu.edu/publications/181_SR/203/203.htm.)

Haug, G. H., and R. Tiedemann (1998), Effect of the formation of the Isthmus of Panama on
Atlantic Ocean thermohaline circulation, Nature, 393, 673-676.

Herbert, T. D., J. D. Schuffert, D. Andreasen, L. Heusser, M. Lyle, A. Mix, A. C. Ravelo, L. D. Stott, and J. C. Herguera (2001), Collapse of the California current during glacial maxima linked to climate change on land, Science, 293, 71-76.

Hodell, D. A., and K. Venz (1992), Toward a high-resolution stable isotopic record of the Southern Ocean during the Pliocene-Pleistocene ( 4.8 to $0.8 \mathrm{Ma})$, in The Antarctic Paleoenvironment: A Perspective on Global Change, Antarct. Res. Ser, vol. 56, edited by J. P. Kennett and D. A. Warnkepp, pp. 265310, AGU, Washington, D. C.

Hodell, D. A., C. D. Charles, and F. J. Sierro (2001), Late Pleistocene evolution of the ocean's carbonate system, Earth Planet. Sci. Lett., 192, 109-124.

Hodell, D. A., C. D. Charles, J. H. Curtis, P. G. Mortyn, U. S. Ninnemann, and K. A. Venz (2003), Data report: Oxygen isotope stratigraphy of ODP Leg 177 Sites 1088, 1089, 1090, 1093, and 1094, Proc. Ocean Drill. Program Sci. Results, 177, 1-26. (Available at http:// www-odp.tamu.edu/publications/177_SR/ volume/chapters/SR177 09.pdf.)

Hovan, S. A., D. K. Rea, and N. G. Pisias (1991), Late Pleistocene continental climate and oceanic variability recorded in northwest Pacific sediments, Paleoceanography, 6, 349-370.

Huybers, P., and C. Wunsch (2004), A depthderived Pleistocene age model: Uncertainty estimates, sedimentation variability, and nonlinear climate change, Paleoceanography, 19, PA1028, doi:10.1029/2002PA000857.

Imbrie, J., and J. Z. Imbrie (1980), Modeling the climatic response to orbital variations, Science, 207, 943-953.

Imbrie, J., J. D. Hays, D. G. Martinson, A. McIntyre, A. C. Mix, J. J. Morley, N. G. Pisias, W. L. Prell, and N. J. Shackleton (1984), The orbital theory of Pleistocene climate: Support from a revised chronology, of the marine $\delta^{18} \mathrm{O}$ record, in Milankovitch and Climate, Part 1, edited by A. Berger, pp. 269-305, Springer, New York.

Imbrie, J., et al. (1992), On the structure and origin of major glaciation cycles: 1. Linear responses to Milankovitch forcing, Paleoceanography, 7, 701-738.

Jenkins, G. M., and D. G. Watts (1968), Spectral Analysis and Its Applications, 525 pp., Holden-Day, Boca Raton, Fla

Jian, Z., Q. Zhao, X. Cheng, J. Wang, P. Wang, and X. Su (2003), Pliocene-Pleistocene stable isotope and paleoceanographic changes in the northern South China Sea, Palaeogeogr Palaeoclimatol. Palaeoecol., 193, 425-442.

Johnsen, S. J., H. B. Clausen, W. Dansgaard, N. Fuhrer, N. S. Gundestrup, C. U. Hammer P. Iverson, J. Jouzel, B. Stauffer, and J. P. Steffensen (1992), Irregular glacial interstadials recorded in a new Greenland ice core, Nature, 364, 218-220.

Karner, D. B., J. Levine, B. P. Medeiros, and R. A. Muller (2002), Constructing a stacked benthic $\delta^{18} \mathrm{O}$ record, Paleoceanography, 17(3), 1030, doi:10.1029/2001PA000667.

Keigwin, L. D., and M. A. Schlegel (2002), Ocean ventilation and sedimentation since the glacial maximum at $3 \mathrm{~km}$ in the western North Atlantic, Geochem. Geophys. Geosyst., 3(6), 1034, doi:10.1029/2001GC000283.

Laskar, J., F. Joutel, and F. Boudin (1993), Orbital, precessional and insolation quantities for the Earth from $-20 \mathrm{Myr}$ to $+10 \mathrm{Myr}$, Astron. d Astrophys., 270, 522-533.

Lisiecki, L. E., and P. A. Lisiecki (2002), Application of dynamic programming to the correlation of paleoclimate records, Paleoceanography, 17(4), 1049, doi:10.1029/ 2001PA000733.

Lourens, L. J., A. Andtonarakou, F. J. Hilgen, A. A. M. Van Hoof, C. Vergnaud-Grazzini, and W. J. Zachariasse (1996), Evaluation of the Plio-Pleistocene astronomical timescale, Paleoceanogrphy, 11, 391-413.

Loutre, M. F., and A. Berger (2003), Marine isotope stage 11 as an analogue for the present interglacial, Global Planet. Change, 36, $209-$ 217.

Mc Intyre, K., A. C. Ravelo, and M. L. Delaney (1999), North Atlantic Intermediate Waters in the late Pliocene to early Pleistocene, Paleoceanography, 14, 324-335.

Mc Intyre, K., M. L. Delaney, and A. C. Ravelo (2001), Millenial-scale climate change and oceanic processes in the late Pliocene and early Pleistocene, Paleoceanography, 16 , 535-543.

McManus, J. F., D. W. Oppo, and J. Cullen (1999), A 0.5-million-year record of millennial-scale climate variability in the North Atlantic, Science, 283, 971-975.

Mix, A. C., N. G. Pisias, R. Zahn, W. Rugh, C. Lopez, and K. Nelson (1991), Carbon-13 in Pacific deep and intermediate waters, $0_{-}$ $370 \mathrm{ka}$ : Implications for ocean circulation and Pleistocene carbon dioxide, Paleoceanography, 6, 205-226.

Mix, A. C., J. Le, and N. J. Shackleton (1995a), Benthic foraminiferal stable isotope stratigraphy from Site 846: 0-1.8 Ma, Proc. Ocean Drill. Program Sci. Results, 138, 839-847.

Mix, A. C., N. G. Pisias, W. Rugh, J. Wilson, A. Morey, and T. K. Hagelberg (1995b), Benthic foraminifer stable isotope record from Site 849 (0-5 Ma): Local and global climate changes, Proc. Ocean Drill. Program Sci. Results, 138, 371-412.

Murray, R. W., C. Knowlton, M. Leinen, A. C. Mix, and C. H. Polsky (2000), Export production and carbonate dissolution in the central equatorial Pacific Ocean over the past $1 \mathrm{Ma}$, Paleoceanography, 15, 570-592.

Ninkovitch, D., and N. J. Shackleton (1975), Distribution, stratigraphic position and age of ash layer "L," in the Panama Basin region, Earth Planet. Sci. Lett., 27, 20-34.

Oppo, D. W., R. G. Fairbanks, A. L. Gordon, and N. J. Shackleton (1990), Late Pleistocene Southern Ocean ${ }^{13} \mathrm{C}$ variability, Paleoceanography, 5, 43-54.

Oppo, D. W., J. F. McManus, and J. L. Cullen (1998), Abrupt climate events 500,000 to 340,000 years ago: Evidence from subpolar North Atlantic sediments, Science, 279 $1335-1338$

Pierre, C., J. F. Saliege, M. J. Urrutiaguer, and J. Giraudeau (2001), Stable isotope record of the last 500 k.y. at Site 1087 (Southern Cape Basin), Proc. Ocean Drill. Program Sci. Results, $175,1-22$. (Available at http://wwwodp.tamu.edu/publications/175_SR/chap_12 chap_12.htm.)

Pisias, N. G., D. G. Martinson, T. C. Moore Jr., N. J. Shackleton, W. Prell, J. Hays, and G. Boden (1984), High resolution stratigraphic correlation of benthic oxygen isotope records spanning the last 300,000 years, Mar. Geol., 56, 119-136.

Pisias, N. G., A. C. Mix, and R. Zahn (1990), Nonlinear response in the global climate sys- 
tem: Evidence from benthic oxygen isotopic record in core RC13-110, Paleoceanography, $5,147-160$

Prell, W. L., J. Imbrie, D. G. Martinson, J. J. Morley, N. G. Pisias, N. J. Shackleton, and H. F. Streeter (1986), Graphic correlation of oxygen isotope stratigraphy: Application to the Late Quaternary, Paleoceanography, 1, $137-162$.

Raymo, M. E. (1997), The timing of major climate terminations, Paleoceanography, 12, $577-585$.

Raymo, M. E., W. F. Ruddiman, and B. M Clement (1986), Plio-Pleistocene paleoceanography of the North Atlantic at Deep Sea Drilling Project Site 609, Initial Rep. Deep Sea Drill. Proj., 94, 895-901.

Raymo, M. E., W. F. Ruddiman, J. Backman, B. M. Clement, and D. G. Martinson (1989), Late Pliocene variation in Northern Hemisphere ice sheets and North Atlantic Deep Water circulation, Paleoceanography, 4 , 413-446.

Raymo, M. E., W. F. Ruddiman, N. J. Shackleton, and D. W. Oppo (1990), Evolution of AtlanticPacific $\delta^{13} \mathrm{C}$ gradients over the last $2.5 \mathrm{~m}$. y., Earth Planet. Sci. Lett., 97, 353-368.

Raymo, M. E., D. Hodell, and E. Jansen (1992), Response of deep ocean circulation to initiation of Northern Hemisphere glaciation (3-2 MA), Paleoceanography, 7, 645-672.

Raymo, M. E., D. W. Oppo, and W. Curry (1997), The mid-Pleistocene climate transition: A deep sea carbon isotopic perspective, Paleoceanography, 12, 546-559.

Raymo, M. E., D. W. Oppo, B. P. Flower, D. A Hodell, J. F. McManus, K. A. Venz, K. F. Kleiven, and K. McIntyre (2004), Stability of North Atlantic water masses in face of pronounced climate variability during the Pleistocene, Paleoceanography, 19, PA2008, doi:10.1029/2003PA000921.

Ruddiman, W. F., M. E. Raymo, D. G. Martinson, B. M. Clement, and J. Backman (1989), Pleistocene evolution of Northern Hemisphere climate, Paleoceanography, 4, 353-412.

Sarnthein, M., K. Winn, S. J. A. Jung, J. C. Duplessy, L. D. Labeyrie, H. Erlenkeuser, and G. Ganssen (1994), Changes in east Atlantic deepwater circulation over the last 30,000 years: Eight time slice reconstructions, Paleoceanography, 9, 209-267.
Shackleton, N. J. (1995), New data on the evolution of Pliocene climate variability, in Paleoclimate and Evolution, With Emphasis on Human Origins, edited by E. S. Vrba et al., pp. 242248, Yale Univ. Press, New Haven, Ct.

Shackleton, N. J., and M. A. Hall (1984), Oxygen and carbon isotope stratigraphy of DSDP Hole 552A: Plio-Pleistocene glacial history, Initial Rep. Deep Sea Drill. Project, 81, 599-609.

Shackleton, N. J., and N. G. Pisias (1985), Atmospheric carbon dioxide, orbital forcing, and climate, in The Carbon Cycle and Atmospheric $\mathrm{CO}_{2}$ : Natural Variations Archean to Present, Geophys. Monogr. Ser., vol. 32, edited by E. Sundquist and W. S. Broecker, pp. $303-$ 317, AGU, Washington, D. C.

Shackleton, N. J., A. Berger, and W. R. Peltie (1990), An alternative astronomical calibration of the Lower Pleistocene timescale based on ODP Site 677, Trans. R. Soc. Edinburgh Earth Sci., 81, 251-261.

Shackleton, N. J., M. A. Hall, and D. Pate (1995a), Pliocene stable isotope stratigraphy of ODP Site 846, Proc. Ocean Drill. Program Sci. Results, 138, 337-356.

Shackleton, N. J., S. Crowhurst, T. Hagelberg, N. G. Pisias, and D. A. Schneider (1995b), A new late Neogene time scale: Application to Leg 138 sites, Proc. Ocean Drill. Program Sci. Results, 138, 73-101.

Shackleton, N. J., M. A. Hall, and E. Vincent (2000), Phase relationships between millennial-scale events 64,000-24,000 years ago, Paleoceanography, 15, 565-569.

Skinner, L. C., and I. N. McCave (2003), Analysis and modeling of gravity- and pistoncoring based on soil mechanics, Mar. Geol. 199, $181-204$.

Stein, M., G. J. Wasserburg, P. Aharon, J. H Chen, Z. R. Zhu, A. Bloom, and J. Chappell (1993), TIMS U-series dating and stable isotopes of the last interglacial event in Papua New Guinea, Geochim. Cosmochim. Acta, 57, 2541-2554

Tian, J., P. Wang, X. Cheng, and Q. Ling (2002), Astronomically tuned Plio-Pleistocene ${ }^{18} \mathrm{O}$ record from South China Sea and AtlanticPacific comparison, Earth Planet. Sci. Lett., 203, 1015-1029.

Tiedemann, R. (1991), Acht Millionen Jahre Klimageschichte von Nordwest Afrika und
Paläo-Ozeanographie des angrenzenden Atlantiks, Ber. Rep. 46, 190 pp., Geol.-Paläontol. Inst. und Mus., Christian-Albrechts-Univ., Kiel, Germany.

Tiedemann, R., and S. O. Franz (1997), Deepwater cicurlation, chemistry, and terrigenous sediment supply in the equatorial Atlantic during the Pliocene, 3.3-2.6 Ma and 5-4.5 Ma, Proc. Ocean Drill. Program Sci. Results, 154, 299-318.

Tiedemann, R., M. Sarnthein, and N. J. Shackleton (1994), Astronomic timescale for the Pliocene Atlantic $\delta^{18} \mathrm{O}$ and dust flux records of Ocean Drilling Program site 659, Paleoceanography, 9, 619-638.

Venz, K. A., and D. A. Hodell (2002), New evidence for changes in Plio-Pleistocene deep water circulation from Southern Ocean ODP Leg 177 Site 1090, Palaeogeogr. Palaeoclimatol. Palaeoecol., 182, 197-220.

Venz, K. A., D. A. Hodell, C. Stanton, and D. A Warnke (1999), A 1.0 Myr record of Glacial North Atlantic Intermediate Water variability from ODP site 982 in the northeast Atlantic Paleoceanography, 14, 42-52.

Waelbroeck, C., J.-C. Duplessy, E. Michel, L. Labeyrie, D. Paillard, and J. Duprat (2001), The timing of the last deglaciation in North Atlantic climate records, Nature, 412, $724-727$.

Williams, D. F., R. C. Thunell, E. Tappa, D. Rio, and I. Raffi (1988), Chronology of the Pleis tocene oxygen isotope record: $0-1.88 \mathrm{~m}$. y. B. P., Palaeogeogr. Palaeoclimatol. Palaeoecol., 64, 221-240.

Zabel, M., T. Bickert, L. Dittert, and R. R. Haese (1999), The significance of the sedimentary $\mathrm{Al} / \mathrm{Ti}$ ratio as indicator for reconstructions of the terrestrial input to the equatorial Atlantic, Paleoceanography, 14, 789-799.

L. E. Lisiecki, Department of Geological Sciences, Brown University, Box 1846, Providence, RI 02912, USA. (lorraine_lisiecki@ brown.edu)

M. E. Raymo, Department of Earth Sciences, Boston University, 685 Commonwealth Avenue, Boston, MA 02215, USA. 